\title{
A Comprehensive Classification of MANETs Routing Protocols
}

\author{
Diaa Eldein Mustafa Ahmed \\ Faculty of Computer Science and Information \\ Technology, Sudan University for Science and \\ Technology, Sudan
}

\author{
Othman O. Khalifa \\ Department of Electrical and Computer \\ Engineering, International Islamic University \\ Malaysia
}

\begin{abstract}
Mobile Ad hoc Networks (MANETs) is self-organized and self-configured networks that doesn't need any cellular infrastructure such as access point (AP), base station (BS) or fixed transmission links. Routing is point of research focus since the invention of commercialized mobile ad-hoc networks. In the literature the classical taxonomy of MANETs routing protocols based on the route computation process subdivided into: Proactive (Table -Driven), Reactive (On-Demand) and Hybrid (inherit both features of the proactive and reactive).However this classification hide other types of MANETs routing protocols play a significant roles nowadays such as(Multicast, Energy and Power- aware, Geographical routing and Hierarchical Routing). This paper provides a comprehensive study of MANETs basic taxonomy of routing protocols. In addition intense comparison between some examples of each routing protocols category has been made to further facilitate research in this area.
\end{abstract}

Keywords: MANET, Routing classification, AODV, OLSR, TORA, ZHLS, LANMAR, CGSR

\section{INTRODUCTION}

The origin of Mobile ad hoc network (MANET) was started in 1970 as packet radio network (PRNET), later on different researches were made on it in different ages, it become popular and gain a great deal of importance from both of the researchers and industry [1]. The Mobile Ad hoc Networks (MANET) is a set of wireless mobile nodes (Mobile phone, laptop, PDA, MP3 player and etc...) which can act as a transmitter, router or receiver. MANET is a peer-to-peer communication technique arises when a group of mobile nodes (MNs) can performed a communications through multi-hop routing using the multi-hop wireless link without centralized administration. MANET is homogeneous when the mobile nodes (MNs) are similar structure, platforms and equal capabilities and responsibilities to perform, and heterogeneous when otherwise. In MANETs mobile nodes that are free in moving in and out in the network, any new node can join the network at any time anywhere, likewise any node can leave the network. MANETs have several prominent features such as topological flexibility, robustness, rapid deployment, inherent mobility support and highly dynamic topology, faultresilience, self-healing and independence of fixed infrastructure spark off many vision based applications[2,3]. Routing protocols establishes the governing rules and define the set of parameters that indicate how the packets are exchanged between communicating nodes of MANETs[2] .Recently there are different routing protocols algorithms are proposed to overcome most of the MANETs challenges such as dynamic topology changes, limited bandwidth, link failure due to node mobility, limited power on mobile nodes, power consumption due to routing computation and etc... This paper provides comprehensive survey for the routing strategies of MANETs and discusses presently offered technological that enhances the overall performance of routing protocols. The rest of this paper is organized as follows. Section II gives an overview of the recent Challenges due to MANETs routing protocols. Section III presents a broadly and comprehensive classification of MANET routing protocols with examples for each one category, in addition provides comparative study between different routing protocols. Finally section IV concludes the paper and presents some future works.

\section{CHALLENGES FACING ROUTING PROTOCOL DESIGN}

MANET works under no fixed infrastructure in which every node works likes a router that stores and forwards packet to final destination. Routing is one of the most challenging tasks in MANETs. Due to its dynamic topology changes, limited bandwidth, limited battery power available in each node, frequent link failure, interference, limited resources and etc., amongst all these characteristics, there are some challenges that protocol designers and network developers are faced with. Therefore routing discovery and maintenance are critical issues in these networks. Here we will focus on most popular and important problems that facing the development of MANET routing protocols[4]:

1-Asymmetric links: Most of the wired networks rely on the symmetric links which are always fixed. But this is not case with MANETs networks as the nodes are mobile and constantly changing their position within network.

2-Routing Overhead: In MANETs networks, nodes often change their location within network due to frequent change in topology and high mobility. So, some stale routes are generated in the routing table which leads to unnecessary routing overhead.

3-Interference: This is the major problem with MANETs networks as links come and go depending on the transmission characteristics, one transmission might interfere with another one and node might overhear transmissions of other nodes and can corrupt the total transmission.

4-Dynamic Topology: Since the topology is not constant; so the mobile node might move or medium characteristics might change. In MANETs networks, routing tables must somehow reflect these changes in topology and routing algorithms have to be adapted. For example in a fixed network routing table updating takes place for every $30 \mathrm{sec}$. This updating frequency might be very low for MANETs networks. 
5-Distributed operation: With no central hierarchy of routers, routing must be distributed amongst the participant nodes.

6-Loop-freedom: Aim to avoid route discovery or maintenance processes from spinning from node to node indefinitely.

\section{7-Demand-based operation versus Proactive}

operation: To minimize the control overhead in the network and thus not waste the network resources (bandwidth, battery, memory, etc...) the protocol should be reactive. This means that the protocol should react only when needed and that the protocol should not periodically broadcast control information.

8-Unidirectional link support: The radio environment can cause the formation of unidirectional links. Utilization of these links and not only the bi-directional links improves the routing protocol performance.

9-Security: Due to the nature of transmission medium, MANET routing protocol is vulnerable to many forms of attacks. They are more prone to security replay transmission, do spoofing threats than other general wired networks because the network structure is not strictly defined. Hello flood attack are common .Also a number of nodes keep on getting added as well as deleted from the network making it very easy for a malicious node to enter a network. Then it will be relatively easy for that node to snoop on network traffic, redirect traffic and flood the entire network. Security is very important to stop any kind of disruption of the network.

10-Power conservation: The nodes in the MANETs network can be laptops and constraint clients such as PDA's that are limited in battery power and therefore uses some standby mode to save the power. It is therefore very important that the routing protocol has support for these sleep modes.

11-Multiple routes: To reduce the number of reactions to topological changes and congestion multiple routes can be used. If one route becomes invalid, it is possible that another stored route could still be valid and thus saving the routing protocol from initiating another route discovery procedure.

12-Quality of Service Support: Most of the group communication technologies support real-time multimedia applications such as video conferencing, video streaming and distributed gaming. These applications require quality-of-service (QoS) aware multicast routing protocol to deliver the same data stream to a predefined group of receivers. Some sort of QoS is necessary to incorporate into the routing protocol.

13-Scalability: Routing protocols should be able to scale with the network size. Scalability can be broadly defined as whether the network is able to provide an acceptable level of service even in the presence of a large number of nodes. In MANET when the network size increases No. of packets send by node also increases that leads to drainage of limited battery power and network life time gets reduced thus scalability is major challenging issue.

14-Energy consumption: In MANETs networks each node participating in the network acts both router and a host and is willing to transfer packets to other nodes. For this purpose, a routing protocol should minimize control traffic. The concept of power as one of the deciding factor in route selection can be crucial in route discovery and route repair phase.

\subsection{Characteristics of an Ideal Routing Protocol for MANETs Network}

A routing protocol should have the following essential characteristics:

- $\quad$ It must be fully distributed.

- Adaptive to frequent change in topology

- Transmission should be reliable to reduce message loss.

- The convergence must be quick, once the network of the topology becomes stable.

- Optimal use of bandwidth, computing power, memory and battery power.

- It must provide a certain level of quality of service (QoS).

- Loop free ,Least control overhead ,Energy -aware, locationaware,

The main design criteria for the routing protocols in

MANETs are as follows:

- Scalability and Reliability

- Dynamic topology

- Maintenance

- Distributed and lightweight

- Simplicity and ease of implementation

- Fault Tolerance

\section{CLASSIFICATION MANETs ROUTING PROTOCOLS}

Routing is a core problem in networks for sending data from one node to another. Routing is point of research focus since the invention of commercialized mobile ad-hoc networks. Several MANET routing protocols have been designed for accurate, fast, reliable, scalable, stable, fairness, robust, QoS aware and energy efficient routing protocols for a high volume of changeable network topology. Such protocols must deal with the typical limitations of changeable network topology, which include high power consumption, low bandwidth, and high error rates. Till to date, number of different routing protocols for mobile ad-hoc networks have been proposed. To establish communication path between nodes, efficient routing protocols are needed. There are number of routing protocols currently available in MANETs. There is a need for a general technique to classify available protocols. As shown in Fig (1-a) MANETs routing protocols it can be divided into two general approaches first one depending on routing strategy and second one based on network structure .Fig(1-b) shown the classification according to the routing strategy, here the routing protocols can be categorized as tabledriven and source initiated. Fig(1-c) shown the classification depending on the network structure, these are classified as flat routing, hierarchical routing, geographical (location based routing), power-aware routing and multicast routing [5].Here in this paper we will focus on routing protocols based on network structure because has gain greet interest from the researchers and industry .

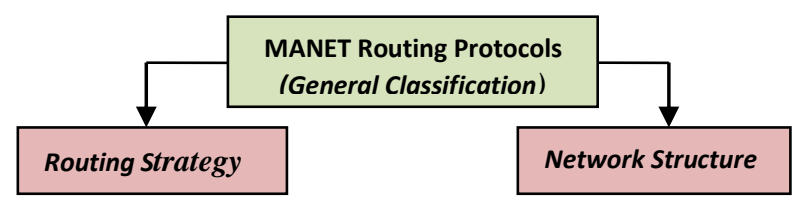

Fig (1-a) MANETs Routing Protocols Main Classification 


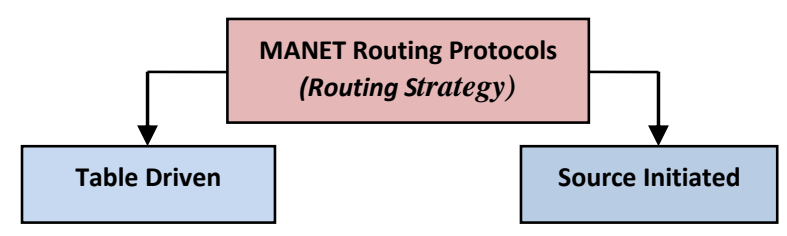

Fig (1-b) MANETs Routing Protocols Classification according to the routing strategy

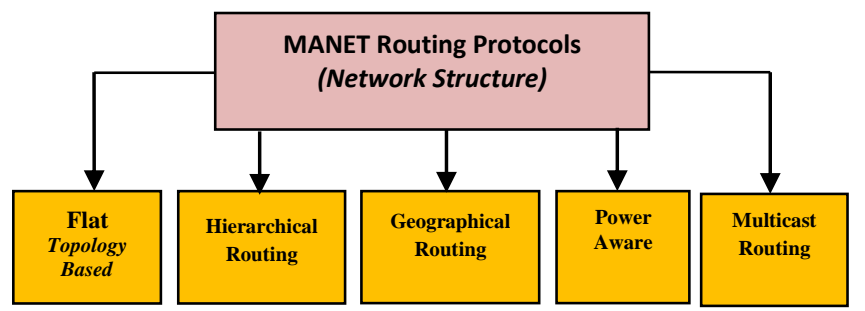

Fig (1-c) MANETs Routing Protocols Classification according to the Network Structure

\subsection{Flat Routing (Uniform) or (Topology Based)}

Topology based routing protocols depend on current topology of the network and cope with the dynamic nature of MANET. The topology-based routing protocols have limited performance when we are comparing with geographical (position based) routing protocols which uses additional information in order to determine the node location. Topology Based Routing schemes generally require additional node topology information during the routing decision process. Topology based routing can be further subdivided into proactive routing protocols(table-driven), reactive routing (on-demand) protocols, and hybrid routing protocols[6, 7]. Fig (2) shows the detailed taxonomy of Flat Routing (Topology Based).

\subsubsection{Proactive or (Table Driven)}

The network is under constant survey in order to know all possible routes between nodes at any given time; this means that routes are constantly being discovered, even if routes have not been invalidated .Maintain table for each node which contains the latest information of routes to nodes, to know its local neighborhood. This control messages are periodically exchanged. Examples of proactive protocols are Destination-Sequenced Distance Vector (DSDV), Optimized Link-State Routing (OLSR), Topology-Based Reverse Path Forwarding (TBRPF) Protocols, and Core-Extraction Distributed Ad hoc Routing (CEDAR). We can distinguish three types of the proactive routing protocols according to the algorithm based on each one.

a) Distance Vector routing: Distant vector protocol is also known as Distributed Bellman-Ford or RIP (Routing Information Protocol) .In a distance vector routing protocol, every host maintains a routing table containing the distances from itself to possible destinations or in other words contains all available destinations details, the next node to reach to destination and the number of hops to reach the destination[8]. Each routing table entry contains two parts: the next hop to the destination, and the distance to the destination. The distance metric might be the number of hops, the delay, the quality of links along the path, etc. The chosen next hops lead to the shortest path to the destination[9]. Using a distance vector protocol, the router simply forwards the packet to the neighboring host (or destination) with the available shortest path in the routing table and assumes that the receiving router will know how to forward the packet beyond that point[10].

\section{Destination Sequenced Distance Vector (DSDV) Protocol}

Is a proactive, hop-by-hop distance-vector routing protocol based on the classical Bellman-Ford routing algorithm proposed by (Charles Perkins and Bhagwatt 1994). It is a distributed, selforganized, and loop-free routing protocol suitable for dynamic networks[11]. Each node maintains a routing table that contains routing entries for all nodes in the network, and periodically advertises and broadcast routing updates of their routing information to their neighbors. Each entry in the routing table contains the destination node's address, next-hop node's address, the number of hops to reach, and the sequence number originated by the destination node. Nodes can forward packets to next-hops, and so on to the destination according to their routing tables. The sequence number is used to distinguish stale routes from new ones and thus avoid loop formation. The stations periodically transmit their routing tables to their immediate neighbors. A station also transmits its routing table if a significant change has occurred in its table from the last update sent. So, the update is both time-driven and event-driven. The routing table updates can be sent in two ways: a "full dump" or an "incremental" update[12].

\section{b) Link State routing:}

In link state protocols, a router doesn't provide the information about the destination instead it provides the information about the topology of the network. This usually consist of the network segments and links that are attached to that particular router along with the state of the link i.e., whether the link is in active state or the inactive state. This information is flooded throughout the network and then every router in the network then builds its own picture of the current state of all the links in the network[10].

\section{Optimized Link State Routing (OLSR) Protocol}

(Jacquet et al 1998) (OLSR) protocol is a proactive routing protocol where the routes are always immediately available when needed. OLSR is an optimization version of a pure link state protocol in which the topological changes cause the flooding of the topological information to all available hosts in the network. OLSR may optimize the reactivity to topological changes by reducing the maximum time interval for periodic control message transmission. Furthermore, as OLSR continuously maintains routes to all destinations in the network, the protocol is beneficial for traffic patterns where a large subset of nodes are communicating with another large subset of nodes, and where the [source, destination] pairs are changing over time[13].

\section{c) QoS proactive routing protocols:}

The primary goal of the QoS-aware routing protocols is to determine a path from a source to the destination that satisfies the needs of the desired QoS. The QoS-aware path is determined within the constraints of bandwidth, minimal search, distance, and traffic conditions. Since path selection is based on the desired QoS, the routing protocol can be termed QoS-aware. In the literature, numerous routing protocols have been proposed for finding QoS paths[14].The most popular examples of the proactive QoS routing protocols is CEDAR, QOLSR, DQRA, In the following section one of these QoS routing protocols is described. 


\section{Core-Extraction Distributed Ad hoc Routing (CEDAR) Protocol:}

(Sivakumar et al 1999) have proposed the Core-Extraction Distributed Ad hoc Routing (CEDAR) algorithm. Is proactive protocol proposed for QoS routing in ad hoc networks for small to medium sized ad hoc networks, the network size may be tens to hundreds of nodes.In CEDAR the bandwidth is used as the only QoS parameter for routing. Most of the multimedia applications require the communication to meet stringent requirements on delay, delay-jitter, cost and other QoS metrics[15]. In these circumstances, the trend is to move from single constrained routing to multi constrained routing. The main function of multi-constrained QoS routing is to find a feasible path that satisfies multiple constraints simultaneously, which is a big challenge for MANETs where the topology may vary constantly.

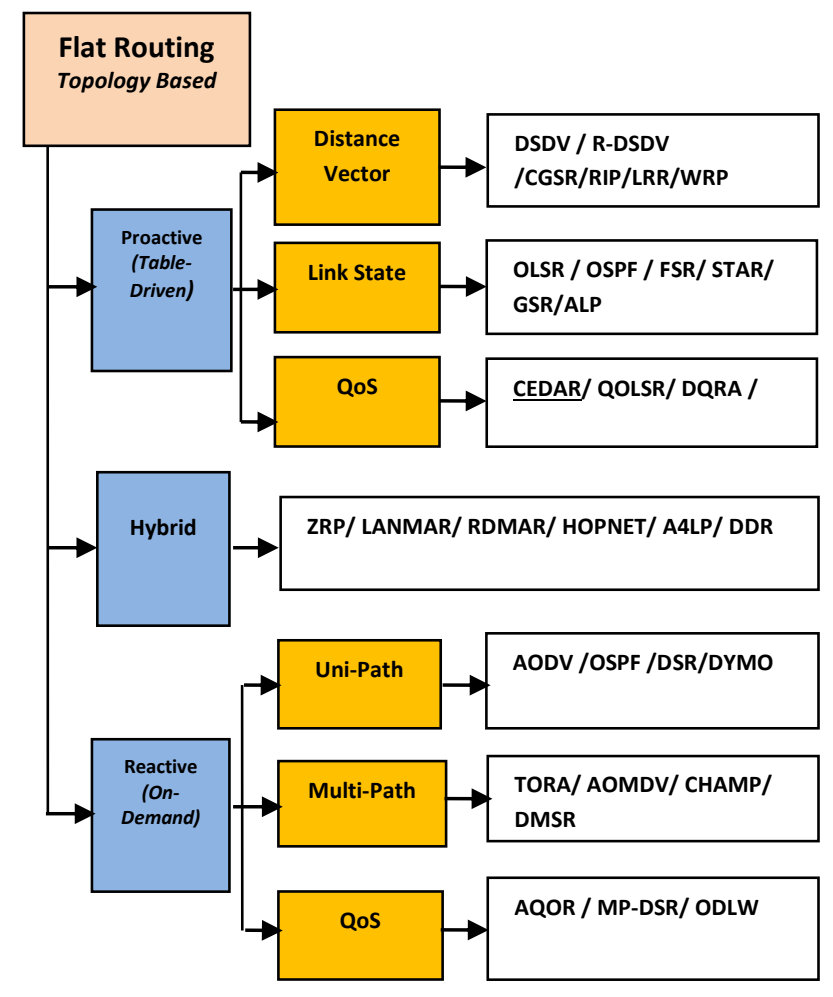

Fig (2) Flat Routing (Topology Based) Classification with subdivisions

CEDAR has three key components: (a) the establishment and maintenance of a self-organizing routing infrastructure, called the "core extraction". During the core extraction a set of nodes is dynamically elected to form the core of the network for performing route computations, (b) the propagation of the linkstate of stable high-bandwidth links in the core through "increase/decrease" waves. During the link state propagation the bandwidth availability information of stable high bandwidth links is propagated to core nodes, while information regarding low bandwidth and unstable links is kept local and (c) a QoS route computation algorithm that is executed at the core nodes using only locally available state[16]. During the last phase, the core path is used to establish a route from the source to the destination[17]. In the CEDAR approach, the core provides an efficient low-overhead infrastructure to perform routing, while the state propagation mechanism ensures availability of link state information at the core nodes without incurring high overheads[18]. The greatest novelties of this technique were the core broadcast and link capacity dissemination mechanisms. These ensure efficient use of network resources and relatively accurate and up-to-date knowledge of the QoS state, where it is required. Furthermore, this protocol does not rely on a TDMA network. However, the problem of estimating available link capacities was left open[19].Table (1) shown a comprehensive comparison between there Flat Routing -Proactive protocols DSDV , OLSR and CEDAR.

\subsubsection{Reactive Routing Protocols (On Demand)}

This type of protocols attempts to establish routes between nodes only when they are needed or when routes are no longer valid. Thus, reactive routing protocols such as AODV try to establish a route to a destination only when needed. Discover routes only on demand basis and do not take initiative for finding a route. Reactive routing needs less memory and storage capacity than proactive protocols. They do not update route tables constantly. Reactive protocol is also known. as the on-demand routing protocol which they don't maintain the routing information or activity of routing at the network nodes which there is no communication. In this protocol, the node wants to send a packet to the other node while for the route in an on-demand routing manner and establish the connection of route to transmit and receive the packet in order to manner. A packets will forward throughout the network by the flooding of the route occurs by the route discovery. The examples of reactive or on-demand routing protocols are: AODV, DYMO, TORA, AQOR, ARA [20].

a) Uni-Path routing: Even if several equally good paths are available, the unipath routing protocols use only one path at a time to a given destination. Such protocols as AODV, OSPF, DSR, and DYMO operate with this strategy. Most routing protocols are unipath or have a unipath mode of operation. A commonly used routing protocol called Open Shortest Path First (OSPF) operates in a unipath mode equal-cost multipath routing is enabled or turned on in the protocol[21].Route discovery and route maintenance are the two steps followed by each protocol. Route discovery: Source node first finds a route or several routes to the destination, when it needs to send packets to a destination. This process is called route discovery. Route maintenance: The source transmits packets with the route. The route may be broken during the transmission of packets, because the node on the route move away or go down. The broken route will be reconstructed. The process of detecting route breakage and rebuilding the route is called route maintenance.

\section{Ad hoc On Demand Distance Vector (AODV)}

AODV (Charles Perkins and Elizabeth Royer 1999; Charles Perkins and Elizabeth Royer 2002; Perkins et al., 2003; Chaudhry et al., 2005; Gorka Hernando et al 2009) is reactive routing protocol belongs to the unipath routing protocols; is on demand routing protocol, whenever a route from source to destination is required then only it develops a route. AODV created with the combination of Dynamic source routing (DSR) and Destination Sequenced Distance-Vector (DSDV); AODV use properties of route request (RREQ) and also route maintenance procedure from DSR and some features like sequence number, periodic updates, hop by hop count from DSDV routing protocol, every node knows its neighbors and the costs to reach them. AODV protocol of MANET doesn't have a fixed topology in a network. This is basically needed for wireless communication for the nodes and 
International Journal of Computer Applications Technology and Research

Volume 6-Issue 3, 141-158, 2017, ISSN:-2319-8656

Table (1) Comparison between the Proactive protocols DSDV, OLSR and CEDAR

\begin{tabular}{|c|c|c|c|c|}
\hline Protocol & \multicolumn{2}{|c|}{$\begin{array}{c}\text { DSDV } \\
\text { Destination sequenced distance vector }\end{array}$} & $\begin{array}{c}\text { OLSR } \\
\text { Optimized Link State Routing } \\
\text { Protocol }\end{array}$ & $\begin{array}{c}\text { CEDAR } \\
\text { Core-Extraction Distributed Ad } \\
\text { Hoc Routing }\end{array}$ \\
\hline $\begin{array}{c}\text { Proactive } \\
\text { type }\end{array}$ & \multicolumn{2}{|r|}{ Distance Vector } & Link State- unicast & QoS Routing \\
\hline $\begin{array}{c}\text { Based } \\
\text { algorithm }\end{array}$ & \multicolumn{2}{|c|}{ Bellman-Ford algorithm } & $\begin{array}{l}\text { - Multipoint Relays (MPRs) } \\
\text { - Optimized link state }\end{array}$ & - (CEDAR) algorithm \\
\hline Advantages & \multicolumn{2}{|c|}{$\begin{array}{l}\text { - Distributed, self-organized, guarantees loop- } \\
\text { free paths to each destination } \\
\text { - Suitable routing protocol for dynamic } \\
\text { networks } \\
\text { - Less delay is involved in the route setup } \\
\text { because of the availability of routes to all } \\
\text { destinations at all times } \\
\text { - DSDV maintains only the best path so the } \\
\text { amount of space in routing table is reduced } \\
\text { - avoid traffic with incremental updates }\end{array}$} & $\begin{array}{l}\text { - Does not need central } \\
\text { administrative system to handle its } \\
\text { routing process } \\
\text { - Well suited for an application } \\
\text { which does not allow long delays in } \\
\text { the transmission of data packets. } \\
\text { - Improve the transmission quality }\end{array}$ & $\begin{array}{l}\text { - It performs both routing and QoS } \\
\text { path computation very efficiently } \\
\text { with the help of core nodes } \\
\text { - utilization of core nodes reduces the } \\
\text { traffic overhead } \\
\text { - Multi constrained routing } \\
\text { - Find a feasible path that satisfies } \\
\text { multiple constraints simultaneously } \\
\text { - Network size may be tens to } \\
\text { hundreds of nodes }\end{array}$ \\
\hline Disadvantages & \multicolumn{2}{|c|}{$\begin{array}{l}\text { - Heavy control overhead because of the } \\
\text { updates due to broken links } \\
\text { - It is not suitable for highly dynamic networks } \\
\text { - DSDV is inefficient due to the requirement of } \\
\text { periodic update transmissions } \\
\text { - To continue an up-to-date view of the } \\
\text { network topology at all the nodes the updates } \\
\text { are propagated throughout the network }\end{array}$} & $\begin{array}{l}\text { - Needs more time to re-discovering } \\
\text { the broken link. } \\
\text { - Requires more power when } \\
\text { discovering alternative route. } \\
\text { - Is not feasible for highly dynamic } \\
\text { networks because of the significant } \\
\text { state propagation overhead when } \\
\text { the network topology changes. }\end{array}$ & $\begin{array}{l}\text { - The movement of the core nodes } \\
\text { affects the performance of the } \\
\text { protocol. } \\
\text {-The update and gathering } \\
\text { information of the whole network } \\
\text { state at each core nodes could cause } \\
\text { a significant or very high of control } \\
\text { overhead. } \\
\text { - does not require high } \\
\text { maintenance overhead even for } \\
\text { highly dynamic networks }\end{array}$ \\
\hline Limitations & \multicolumn{2}{|c|}{$\begin{array}{l}\text {-DSDV doesn't support Multi path Routing. } \\
\text { - It is difficult to determine a time delay for the } \\
\text { advertisement of routes } \\
\text { - It is difficult to maintain the routing table's } \\
\text { advertisement for larger network. } \\
\text { - The route is decided through the sequence } \\
\text { number } \\
\text { - }\end{array}$} & $\begin{array}{l}\text { - Wider delay distribution } \\
\text { - This protocol needs that each node } \\
\text { periodically sends the updated } \\
\text { topology information throughout } \\
\text { the entire network, this increase } \\
\text { the protocols bandwidth usage } \\
\text { - Needs more time to re-discovering } \\
\text { the broken link. } \\
\text { - OLSR requires more power when } \\
\text { discovering alternative route. }\end{array}$ & $\begin{array}{l}\text { - Route establishment and } \\
\text { computation is relied on core nodes. } \\
\text { - Estimating available link capacities } \\
\text { was left open } \\
\text { - Unicast-based "core broadcast" for } \\
\text { reliability }\end{array}$ \\
\hline $\begin{array}{l}\text { Enhanced } \\
\text { versions } \\
\text { (Extensions) }\end{array}$ & \multicolumn{2}{|c|}{$\begin{array}{l}\text { - Research work on improvement of DSDV is } \\
\text { still active. Many improved protocols based on } \\
\text { DSDV have been developed. These } \\
\text { improvements of DSDV include Global State } \\
\text { Routing (GSR), Fisheye State Routing (FSR), Ad } \\
\text { Hoc On-Demand Distance Vector Routing } \\
\text { (AODV) }\end{array}$} & $\begin{array}{l}\text {-HOLSR and EE-OLSR proposed } \\
\text { based on OLSR with hierarchical } \\
\text { architecture and Energy Efficient } \\
\text {-QOLSR (Support quality of service ) } \\
\text {-Geo-OLSR( support geographical } \\
\text { location information service) }\end{array}$ & $\begin{array}{l}\text { - MCEDAR (Multicast ) provides the } \\
\text { robustness of mesh based routing } \\
\text { protocols } \\
\text { - Recent research works towards } \\
\text { combines CEDAR with DSR and AODV } \\
\text { to propose DSRCEDAR and } \\
\text { AODVCEDAR }\end{array}$ \\
\hline \multirow{6}{*}{$\begin{array}{c}\text { Performance } \\
\text { Metrics and } \\
\text { QoS } \\
\text { parameters }\end{array}$} & Throughput & $\begin{array}{l}\text { - Least very low when } \\
\text { compared with DSR, OLSR } \\
\text { and AODV }\end{array}$ & $\begin{array}{l}\text { - High when compared with other } \\
\text { link state protocols[22] }\end{array}$ & \multirow[t]{5}{*}{$\begin{array}{l}\text { - Stable high bandwidth } \\
\text {-MCEDAR is the enhanced version } \\
\text { support multicasting mechanism }\end{array}$} \\
\hline & $\begin{array}{l}\text { Packet/dropp } \\
\text { ed/loss }\end{array}$ & - high & $\begin{array}{l}\text { - Packet loss rate is less because } \\
\text { most of the Packets sent and } \\
\text { received is among the MPR nodes }\end{array}$ & \\
\hline & $\begin{array}{l}\text { End to end } \\
\text { delay and } \\
\text { jitter }\end{array}$ & $\begin{array}{l}\text { - Least and remains constant as } \\
\text { the number of nodes increase } \\
\text { in the networks. }\end{array}$ & $\begin{array}{l}\text { - Average end to end delay and least } \\
\text { compared to DSDV }\end{array}$ & \\
\hline & $\begin{array}{c}\text { Packet } \\
\text { Delivery } \\
\text { Ratio (PDR): }\end{array}$ & $\begin{array}{l}\text { - Increases initially then Low } \\
\text { compared to OLSR }\end{array}$ & $\begin{array}{l}\text { - higher packet delivery ratio with } \\
\text { compared to DSDV }\end{array}$ & \\
\hline & $\begin{array}{l}\text { Routing } \\
\text { Overhead }\end{array}$ & $\begin{array}{l}\text { - Very high for a slight increase } \\
\text { in the number of nodes }\end{array}$ & - Low (reduces the routing overhead) & \\
\hline & $\begin{array}{l}\text { Caching } \\
\text { Overhead }\end{array}$ & -Medium & -High & -low \\
\hline
\end{tabular}


path from which request packet come. Following information is contained in the packet header for route request:

- $\quad$ Source node IP address

- $\quad$ Broadcast ID

- Current sequence number for the destination

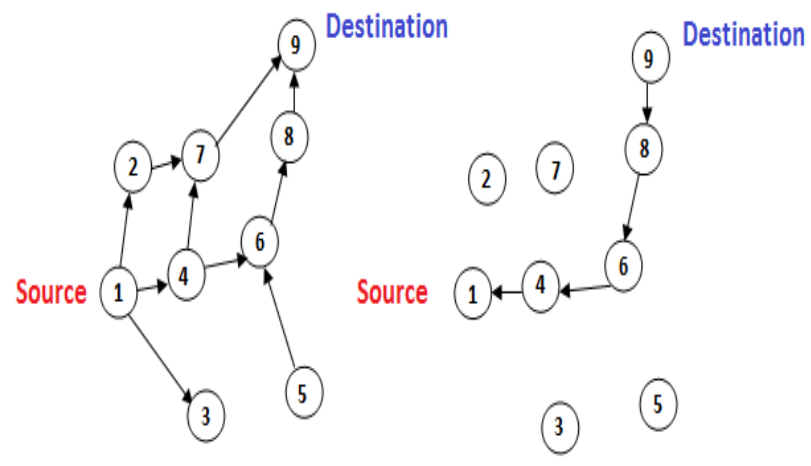

Figure (3): AODV Route Discovery

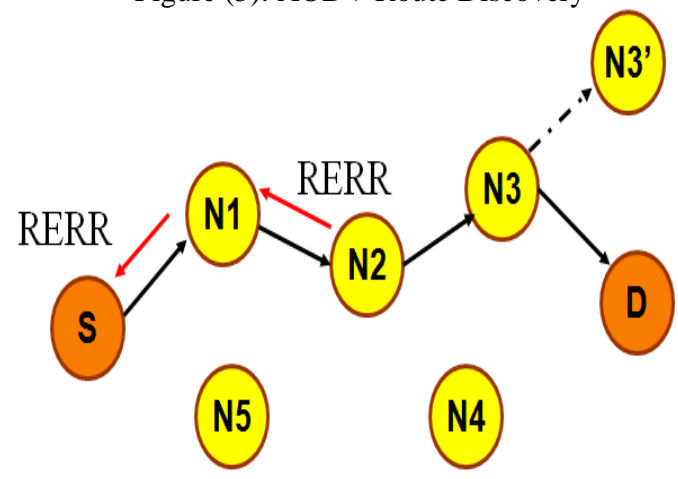

Figure (4) AODV Route Maintenance Process

During a route discovery process as shown in Figure (3), the source node broadcasts a route query packet to its neighbors. If any of the neighbors has a route to the destination, it replies to the query with a route reply packet; otherwise, the neighbors rebroadcast the route query packet. Finally, some query packets reach to the destination. The route maintenance process in AODV is very simple (as shown in Figure (4)). When the link in the communication path between node $\mathrm{S}$ (source node) and node $\mathrm{D}$ (Destination node) breaks the upstream node that is affected by the break, in this case node N2 generates and broadcasts a RERR message. The RERR message eventually ends up in source node $S$. After receiving the RERR message, node $S$ will generate a new RREQ message.

\section{b) Multi-Path routing:}

In single path routing protocols, a single route is discovered between source and destination. Discovery of multiple routes between source and destination in single route discovery is done by multipath routing. Multipath Routing is the process of distributing the data from source node to destination node over multiple paths. Multipath algorithms permit traffic multiplexing over multiple paths. Multipath Routing performs better by proper usage of network resources. Multipath routing protocols provides better throughput and reliability than single path protocols. The main goals of multipath routing protocols are to maintain reliable communication, to reduce routing overhead by use of secondary paths, to ensure load balancing, to improve quality of service, to avoid the additional route discovery overhead[23].

Temporally Ordered Routing Algorithm (TORA)

TORA (Park and Corson 1997) is a source-initiated on-demand routing protocol, which uses a link reversal algorithm and provides loop-free multipath routes to a destination node. In TORA, each node maintains its one-hop local topology information and also has the capability to detect partitions. TORA is proposed to operate in a highly dynamic mobile networking environment. The key design concept of TORA is the location of control messages sent to a very small set of nodes near the occurrence of a topological change. The protocol performs three basic functions: (1) route creation, (2) route maintenance, and (3) route erasure. During the route creation and maintenance phases, the nodes use a height metric, which establishes a direct acyclic graph (DAG) rooted at the destination. Therefore, links are assigned a direction (upstream or downstream) based on the relative height metric of neighboring nodes, as shown in Figure (5). The process for establishing a DAG is similar to the query/reply process in lightweight mobile routing. In times of node mobility, the DAG route is broken, and route maintenance is necessary to reestablish a DAG rooted at the same destination. Timing is an important factor for TORA because the height metric depends on the logical time of link failure. TORA assumes all nodes have synchronized clocks. In TORA, there is a potential for oscillations to occur, especially when multiple sets of coordinating nodes are concurrently detecting partitions, erasing routes, and building new routes based on each other. Because TORA uses inter nodal coordination, its instability problem is similar to the "count-to-infinity" problems.

\section{QoS reactive routing protocols:}

In any given network, there are two types of flows in general: BE (Best Effort) flows which require the data to be reliably delivered to the destination, and QoS flows such as RT (Real Time) which apart from reliability, requires some additional constraints such as available bandwidth, delay, etc. to be satisfied[24] . Reusing BE routing methods for QoS-aware routing is not feasible since BE routing performs these tasks based on a single measure, usually hop-count while QoS-aware routing, however, must take into account multiple QoS measures and requirements. This section discusses different QoS-aware routings in MANETs from different perspectives including its challenges, classifications, algorithms and comparisons.

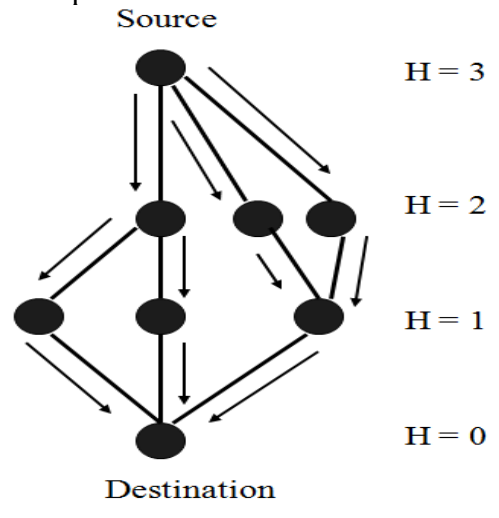

Figure (5) TORA routing scheme 


\section{Ad hoc QoS on-demand routing (AQOR)}

Is a resource reservation and signaling algorithm proposed by (Xue and Ganz 2003). AQOR is a reactive QoS routing protocol guarantee smallest end-to-end delay and bandwidth in MANETs [18]. Uses limited flooding to discover the best route available in terms of smallest end-to-end delay with bandwidth guarantee. A route request packet includes both bandwidth and end to-end delay constraints . This protocol mainly used to provides end-toend QoS support in terms of bandwidth and end-to-end delays in MANETs. It is a resource reservation-based routing and signaling scheme that allows AQOR to make admission and resource reservation decisions. AQOR integrates on-demand route discovery between the source and the destination, signaling functions for resource reservation and maintenance and hop-byhop routing. AQOR is also a source initiated, on-demand routing protocol. It is built upon AODV routing, performing exploration of routes only when required. The route discovery mechanism is in on-demand mode, broadcasting the RREQ and RREP packets between the source and destination nodes. The route discovery mechanism starts when the node broadcasts RREQ packets with QoS requirements to its neighboring nodes. The neighboring nodes that satisfy the requirement add a route entry to the source node's routing table and forward the RREQ until it reaches the destination. When the RREQ reaches the destination node, an RREP is sent back along the reverse route, reserving bandwidth at each node. Once the source node receives the RREP, it starts sending data out along the reserved route. AQOR uses timers to detect route breaks and to trigger route recovery. If any node fails to receive a data packet before its reservation expires, a route recovery mechanism is triggered. Source node starts the route discovery process all over again by broadcasting an RREQ packet. Initiating a route discovery process each time a route break occurs can lead to high end-to-end delays. AQOR uses routing tables for keeping track of its routes. Every time a route failure occurs, AQOR must update its routing table entries, which may sometimes result in inconsistent entries due to the high dynamic nature of the network topology. To avoid possible loops during route exploration, AQOR uses a route sequence number to indicate the freshness of the control packets for each follow. The sequence number is maintained at each mobile node aware of the follow. The initial sequence number of any follow is 0 . When sending out a route control packet for a follow (e.g., RREQ, REP, or RERR), the initial node will increase its current sequence number by 1 and attach the value to the packet .In AQOR, the route with the shortest end-to-end delay, given it satisfies the bandwidth requirement, is selected. This protocol mainly used to bandwidth and End-to-End delay. This protocol is guarantee for smallest end - to- end delay and bandwidth[18]. A Bandwidth and end-to-end delay constraints are included in route request packet. Table (2) shown a comparison between three types of Flat-routing (Reactive Protocols) AODV, TORA and AQOR.

3.1.3 Hybrid Routing Protocols: is a combination of reactive and proactive routing protocols. These protocols have the advantage of both proactive and reactive routing protocols to balance the delay which was the disadvantage of table driven protocols and control overhead (in terms of control packages). Main feature of Hybrid Routing protocol is that the routing is proactive for short distances and reactive for long distances E.g. ZRP, LANMAR, HOPNET, and DDR.

\section{Zone Routing Protocol (ZRP)}

(Pearlman and Haas 1999), as seen, proactive routing uses excess bandwidth to maintain routing information, while reactive routing involves long route request delays. Reactive routing also inefficiently floods the entire network for route determination[25]. ZRP divides the entire network into overlapping zones of variable size where routing inside the zone is performed using proactive approach and outside the zone is performed using reactive approach[26].

\subsection{Hierarchical routing}

The idea behind hierarchical routing is to divide the hosts of selforganized networks into a number of overlapping or disjointed clusters[27] .Hierarchical-Network is used when the size of network inside a MANET increases tremendously[7]. Hierarchical routing protocols organize the network as a tree of clusters, where the roles and functions of nodes are different at various levels of the hierarchy. Routes are constructed according to the node's position in the virtual hierarchy[11]. Non-uniform hierarchical routing protocols can be further sorted into three subcategories: zone-based, cluster-based, and core-based. These protocols are categorized according to the organization of the mobile nodes, their respective management and their routing functions. Fig (6) shown the subcategories of MANETs hierarchical routing protocols.

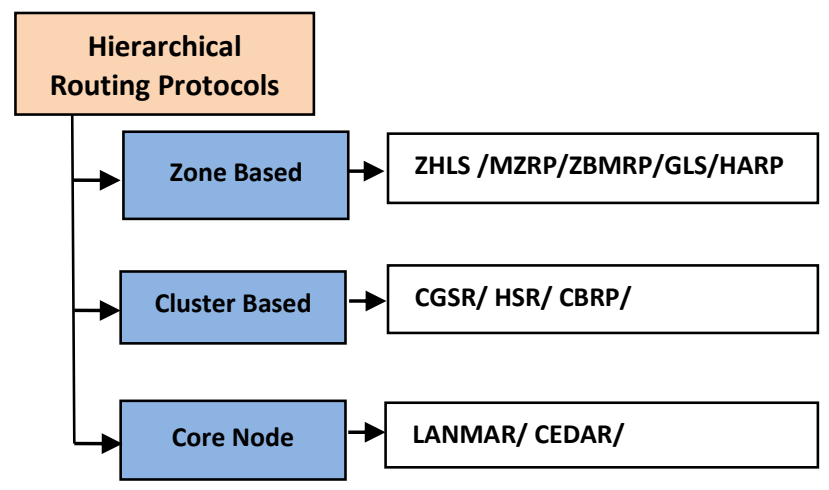

Fig (6) Hierarchical Routing Classification

\subsubsection{Zone Based}

With zone-based hybrid routing algorithm technique each node has a local scope and different routing strategies are used, inside and outside the scope, as communications pass across the overlapping scopes. Given this flexibility, a more efficient overall routing performance can be achieved. Compared to maintaining routing information for all nodes in the whole network, mobile nodes in the same zone know how to reach each other with a smaller cost. In some zone-based routing protocols, specific nodes act as gateway nodes and carry out inter-zone communication. Therefore, the network will contain partitions or a number of zones. The Zone Routing Protocol (ZRP) is a MANET zone-based hierarchical routing protocol[28].

\section{Zone-Based Hierarchical Link State Routing Protocol (ZHLS)}

ZHLS (Joa Ng and Lu 1999) is a hierarchical routing protocol, and it is a zone-based hierarchical protocol that makes use of location information in a novel peer-to-peer hierarchical routing approach[27]. In ZHLS, the network is divided into nonoverlapping clusters (zones) without any masters (zone-heads) as 
shown in Fig. (7). In ZHLS, mobile nodes are assumed to know their physical locations with assistance from a locating system like GPS. In ZHLS protocol, the network is divided into non-over lapping zones as in cellular networks[29]. Each node has own node ID and a zone ID, which is calculated by using the GPS[20]. This topology made up to two levels: node level topology and zone level topology. Each node knows the node connectivity within its own zone and the zone connectivity information of the entire network. The link state routing is performed by employing two levels: node level and global zone level. ZHLS does not have any cluster head in the network like other hierarchical routing protocols.

\subsubsection{Cluster Based}

A cluster based routing protocol is the most popular hierarchical routing technique. The process of dividing the network into interconnected sub structures is called clustering and the interconnected substructures are called clusters. The cluster head $(\mathrm{CH})$ of each cluster act as a coordinator within the substructure. Each $\mathrm{CH}$ acts as a temporary base station within its zone or cluster. It also communicates with other $\mathrm{CHs}[30]$. The Cluster based routing provides an answer to address nodes heterogeneity, and to limit the amount of routing information that propagates inside the network. A cluster-based routing protocol uses specific clustering algorithms for cluster

head election. Mobile nodes are grouped into clusters and cluster heads take the responsibility for membership management and routing functions. CGSR will be introduced in this section as an example of cluster-based mobile ad hoc network routing protocols. Some cluster-based MANETs routing protocols potentially support a multilevel cluster structure, such as hierarchical state routing (HSR) [27].

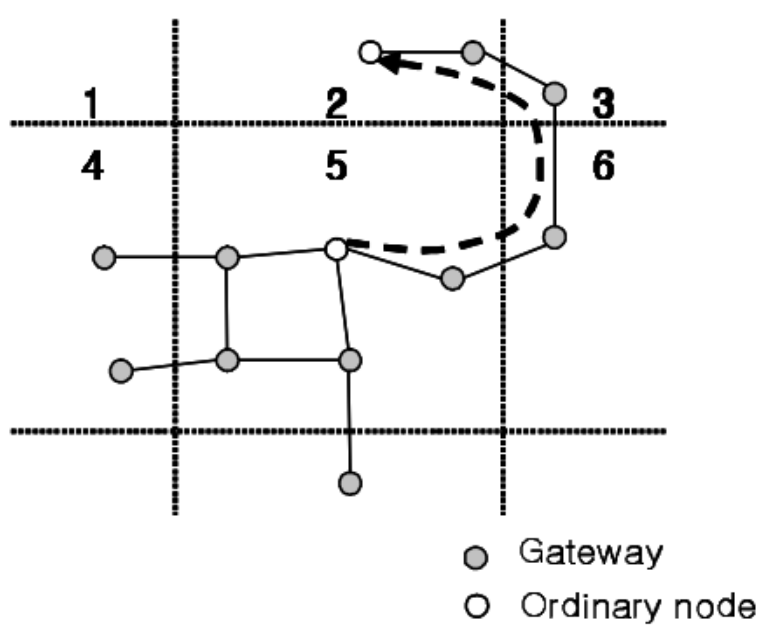

Fig (7) ZSLS routing(Zone 5 and 6 are connected but 2 and 5 are not) [31]

\section{Cluster-Head Gateway Switch Routing (CGSR)}

(CGSR) (Chiang et al 1997) [32] is a hierarchical routing protocol. The cluster structure improves performance of the routing protocol because it provides effective membership and traffic management. Besides routing information collection, update and distribution, cluster construction and cluster-head selection algorithms are important components of cluster based routing protocols. The CGSR protocol is a clustering scheme that uses a distributed algorithm called the Least Cluster Change
(LCC)[33]. CGSR extends DSDV with a cluster framework concept that increases protocol scalability, also, heuristic methods like priority token scheduling, gateway code scheduling, and path reservation are used to improve the protocol's performance. On the other hand, setting up structure in a highly dynamic environment can adversely affect protocol performance since the structure might not persist for a very long time [34]. CGSR is multi-channel routing protocol is generally used in TDMA or CDMA-based networks. They combine channel assignment and routing functionality. CGSR is a non-uniform hierarchical protocol, which is based to forming clusters among nodes and selecting a cluster head to control routing to outside the cluster area.[35]. By aggregating nodes into clusters controlled by cluster heads, a framework for developing additional features for channel access, bandwidth allocation, and routing is created. Nodes communicate with the cluster head, which, in turn, communicate with other cluster heads within the network. Selecting a cluster head is a very important task because frequently changing cluster heads will have an adverse effect on the resource allocation algorithms that depend on it. Thus cluster stability is of primary importance in this scheme. The LCC algorithm is stable in that a cluster head will change only under two conditions: when two cluster heads come within the range of each other or when a node gets disconnected from any other cluster. CGSR is an effective way for channel allocation within different clusters by enhancing spatial reuse. The explicit requirement of CGSR on the link layer and MAC scheme is as follows: (1) Each cluster is defined with unique CDMA code and hence each cluster is required to utilize spatial reuse of codes. (2) Within each cluster, TDMA is used with token passing. Gateway nodes are defined as those nodes which are members of more than one cluster and therefore need to be communicating using different CDMA codes based on their respective cluster heads. The main factors affecting routing in these networks are token passing (in cluster heads) and code scheduling (in gateways). This uses a sequence number scheme as in DSDV to reduce stale routing table entries and gain loop-free routes. A packet is routed through a collection of these cluster heads and gateways in this protocol. In CGSR, when forwarding a packet, a node firstly checks both its cluster member table and routing table and tries to find the nearest cluster-head along the routing path. As shown in Figure (8), when sending a packet, the source (node 1) transmits the packet to its cluster-head (node 2). From the cluster-head node 2, the packet is sent to the gateway node (node 3 ) that connecting to this cluster-head and the next cluster-head (node 5) along the route to the destination (node 8). The gateway node (node 6) sends the packet to the next clusterhead (node 7), i.e. the destination cluster-head. The destination cluster-head (node 7) then transmits the packet to the destination (node 8).

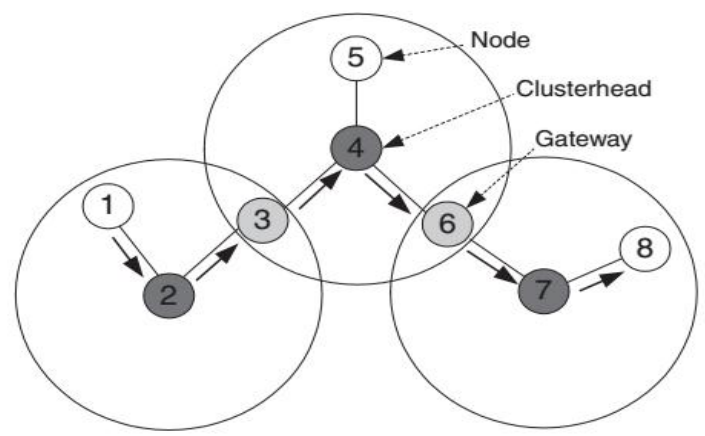

Fig (8) Cluster Structure in CGSR [32] 
International Journal of Computer Applications Technology and Research

Volume 6-Issue 3, 141-158, 2017, ISSN:-2319-8656

Table (2) Comparison between the reactive protocols AODV, TORA, AQOR

\begin{tabular}{|c|c|c|c|c|}
\hline & \multicolumn{2}{|c|}{ AODV } & TORA & AQOR \\
\hline Reactive type & \multicolumn{2}{|c|}{ Uni-path (unicast) } & Multi-path & QoS \\
\hline Advantages & \multicolumn{2}{|c|}{$\begin{array}{l}\text { - Provides loop-free multipath routes to a } \\
\text { destination node } \\
\text { - Reliable and offers quick adaptation to dynamic } \\
\text { link conditions } \\
\text { - Less delay in connection setup. } \\
\text { - Low processing and memory overhead } \\
\text { - Low network utilization } \\
\text { - Determines unicast between sources and } \\
\text { destinations. } \\
\text { - The HELLO messages supporting the route } \\
\text { maintenance are range limited, so they do not } \\
\text { cause unnecessary overhead in the network } \\
\text { - It uses destination sequence numbers to ensure } \\
\text { loop freedom at all times (even in the face of } \\
\text { anomalous delivery of routing control messages) } \\
\text { - Solving problems (such as "counting to infinity") } \\
\text { associated with classical distance vector protocols. } \\
\text { - Coping up with dynamic topology and broken links } \\
\text { - Highly Scalable }\end{array}$} & $\begin{array}{l}\text { - Supports multiple routes between } \\
\text { source and destination. Hence, } \\
\text { failure or removal of any of the } \\
\text { nodes quickly resolved without } \\
\text { source intervention by switching } \\
\text { to an alternate route to improve } \\
\text { congestion. } \\
\text { - Provides the supports of link } \\
\text { status sensing and neighbor } \\
\text { delivery, reliable, in-order control } \\
\text { packet delivery and security } \\
\text { authentication. } \\
\text { - TORA discovers new route faster } \\
\text { and more effectively to the } \\
\text { destination when the old route is } \\
\text { broken as it invokes route repair } \\
\text { mechanism locally also high route } \\
\text { cache hit ratio in TORA. } \\
\text { - Operate in a highly dynamic } \\
\text { mobile networking environment }\end{array}$ & $\begin{array}{l}\text { - Provide QoS support in } \\
\text { terms of bandwidth and } \\
\text { end-to-end delay. } \\
\text {-AQOR's route firm is quick } \\
\text { and reliable. } \\
\text {-AQOR's traffic } \\
\text { measurements and } \\
\text { admission decisions are } \\
\text { accurate and provide high } \\
\text { channel utilization. } \\
\text { - The route with the least } \\
\text { delay is chosen by the } \\
\text { source }\end{array}$ \\
\hline Disadvantages & \multicolumn{2}{|c|}{$\begin{array}{l}\text { - High route discovery latency, AODV does not } \\
\text { discover a route until a flow is initiated } \\
\text { - Multiple Route Reply packets in response to a } \\
\text { single Route Request packet can lead to heavy } \\
\text { control overhead } \\
\text { - Routing table entries are purged (deleted) after a } \\
\text { certain period of time even if any or some of the } \\
\text { links are valid. } \\
\text { - Periodic exchange of beacons for detecting broken } \\
\text { links consumes bandwidth }\end{array}$} & $\begin{array}{l}\text { - Same as on-demand routing } \\
\text { protocols. } \\
\text { - Not much used since DSR and } \\
\text { AODV outperform TORA. } \\
\text { - TORA support unidirectional links } \\
\text { and multiple routing paths }\end{array}$ & $\begin{array}{l}\text { - Initiating a route } \\
\text { discovery process each } \\
\text { time a route break occurs } \\
\text { can lead to high end-to- } \\
\text { end delays. }\end{array}$ \\
\hline $\begin{array}{l}\text { Enhanced } \\
\text { versions }\end{array}$ & \multicolumn{2}{|c|}{$\begin{array}{l}\text {-AOMDV(multicast) , PAAODV(power-aware) , } \\
\text { EAODV(Energy-aware) }\end{array}$} & - PDTORA & - \\
\hline Limitations & \multicolumn{2}{|c|}{$\begin{array}{l}\text { - Requirement on broadcast medium } \\
\text {-AODV lacks support for high throughput routing } \\
\text { metrics } \\
\text { - It is vulnerable to misuse } \\
\text { - AODV doesn't support multiple routing paths } \\
\text { - Large delay caused by route discovery process }\end{array}$} & $\begin{array}{l}\text { - Not scalable by any means } \\
\text { - TORA assumes all nodes have } \\
\text { synchronized clocks } \\
\text { - In TORA, oscillations may occur } \\
\text { when coordinating nodes } \\
\text { currently execute the same } \\
\text { operation }\end{array}$ & $\begin{array}{l}\text { - Every time a route failure } \\
\text { occurs, AQOR must } \\
\text { update its routing table } \\
\text { entries, which may } \\
\text { sometimes result in } \\
\text { inconsistent entries due } \\
\text { to the high dynamic } \\
\text { nature of the network } \\
\text { topology }\end{array}$ \\
\hline $\begin{array}{c}\text { Based } \\
\text { algorithm }\end{array}$ & \multicolumn{2}{|c|}{ - Builds on the DSDV algorithm } & $\begin{array}{l}\text { - Link reversal algorithm and } \\
\text { Directed Acyclic Graph (DAG) }\end{array}$ & $\begin{array}{l}\text { - Resource reservation- } \\
\text { based routing and } \\
\text { signaling algorithm }\end{array}$ \\
\hline \multirow{7}{*}{$\begin{array}{l}\text { Performance } \\
\text { Metrics and } \\
\text { QoS } \\
\text { parameters }\end{array}$} & Throughput & $\begin{array}{l}\text { - Poor for more than } 20 \\
\text { Mobiles }\end{array}$ & - Better throughput & \multirow{6}{*}{$\begin{array}{l}\text { - Based on Bandwidth and } \\
\text { Delay only } \\
\text { - Bandwidth Utilization: } \\
\text { Minimum bandwidth } \\
\text { - end to end delay: } \\
\text { Maximum end-to-end } \\
\text { delay }\end{array}$} \\
\hline & Packet dropped & -Minimum & -Moderate & \\
\hline & $\begin{array}{l}\text { Jitter and end to } \\
\text { end delay }\end{array}$ & $\begin{array}{l}\text { - high initially in AODV but } \\
\text { after some time it is very low } \\
\text { - as the number of nodes are } \\
\text { increasing the delay of AODV } \\
\text { is increasing }\end{array}$ & - High compared to DSR & \\
\hline & $\begin{array}{l}\text { Packet Delivery } \\
\text { Ratio(PDR): }\end{array}$ & -High & - High & \\
\hline & $\begin{array}{l}\text { Routing } \\
\text { Overhead }\end{array}$ & $\begin{array}{l}\text { - AODV has less traffic } \\
\text { overhead, but compared to } \\
\text { DSDV is high }\end{array}$ & - Low compared to DSR & \\
\hline & $\begin{array}{l}\text { Bandwidth } \\
\text { Utilization }\end{array}$ & $\begin{array}{l}\text { - Overhead on the bandwidth } \\
\text { because RREQ travels from } \\
\text { node to node in the process } \\
\text { of discovering the route info } \\
\text { on demand, it automatically } \\
\text { sets up the reverse path from } \\
\text { all nodes back to the source }\end{array}$ & $\begin{array}{l}\text { - Since TORA does not require a } \\
\text { periodic update, consequently } \\
\text { communication overhead and } \\
\text { bandwidth utilization is } \\
\text { minimized. }\end{array}$ & \\
\hline & $\begin{array}{l}\text { Caching } \\
\text { Overhead }\end{array}$ & - Low & -Medium & \\
\hline
\end{tabular}




\subsection{3-Core Node}

In core node-based routing protocols, critical nodes are dynamically selected to compose a "backbone" for the network. The "backbone" nodes carry out special functions, such as the construction of routing paths and propagation of control/data packets. Optimized Link State Routing (OLSR) and Core Extraction Distributed Ad hoc Routing (CEDAR) protocols are typical core node-based MANET routing protocols[28].

\section{Landmark Ad Hoc Routing (LANMAR)}

In the Fisheye State Routing protocol (FSR) (Pei et al 2000a), every node in the network needs to maintain whole network topology information. This strictly limits its scalability. The Landmark Ad hoc Routing (LANMAR) (Pei et al 2000b) is proposed as a modification of FSR and aims to gain better scalability. In contrast to FSR, LANMAR belongs to the nonuniform routing category of mobile ad hoc networks. In LANMAR, mobile nodes are divided into predefined logical subnets according to their mobility patterns, i.e., all nodes in a subnet are prone to move as a group. A landmark node is prespecified for every logic subset to keep track of the subnet. Using LANMAR; every mobile node has a hierarchical address that includes its subnet identifier. A node maintains the topology information of its neighbors and all landmark nodes, which represent logical subnets. Similar to FSR, neighboring nodes in LANMAR periodically exchange topology information and the distance vector of landmark nodes. When a source sends packets to the destination inside its neighboring scope (i.e., the source and the destination belong to the same subnet), desired routing information can be found from the source's routing table. Otherwise, the subnet identified in the destination node's address will be searched. Then, according to the distance vector, the packets will be routed towards the landmark node of the logical subset. Compared to FSR, LANMAR is more efficient because the need to exchange topology information is reduced substantially. However, LANMAR assumes that nodes are grouped into subsets according to their movement patterns and the membership of each subnet remains unchanged during the lifetime of the network, so it is only suitable for specific application scenarios. Table (3) illustrates a comparison between a three major Hierarchical protocols ZHLS, CGSR and LANMAR.

3.3Geographic Position (Information Assisted) Geographic routing (also called geo-routing or position-based routing) is a routing principle that relies on geographic position information. Geographical routing protocols are topological independent, developed for large and distributed network operations. Generally, in traditional MANETs, the nodes are addressed only with their IP addresses[29]. But, in case of location-aware routing mechanisms, the nodes are often aware of their exact physical locations in the three-dimensional world within the network. The proactive zones act as collectors of the GPSs, which are embedded in nodes, are used to update information in tables in position-based algorithms. That makes position-based algorithms different from the table driven and on demand algorithms[36].This type of protocols is mainly proposed for mobile wireless networks and based on the idea that the source sends a message to the geographic location of the destination instead of using the network address. Geographic routing is a technique to deliver a message to a node in a network over multiple hops by means of position information[5]. Node use broadcast to know location of one hope neighbor. Due to this position -based routing required minimal routing overhead and also avoid delay and latency due to localized forwarding. Routing decisions are not based on network addresses and routing tables; instead, messages are routed towards a destination location. Geographic Position (Information assisted) protocols is used to eliminate the limitations of topology based routing by using additional information. It gives the better performance in dynamic topologies because the packets are forwarded to its destination with respect to its position. Each node determines its own position and for determining the position of the network node the different positioning schemes are used such as GPS, GPRS etc. Location-aware routing does not require the routes establishment and maintenance. No routing information is stored. Typically, a node selects the next hop for packets forwarding by using the physical position of its one-hop neighbors and the physical position of the destination node; positioning information of the networks' nodes are usually obtained via queries offered through some location service[34] .Fig (9) shows the different categories of the location aware or geographical position routing technique. Generally this type can subdivided into three main approaches with respect to path strategy and packet forwarding : greedy (single-path), flooding (multi-path) and hierarchical [37, 38]. In the next section we will discuss and explain each category aided with examples of protocols such as GPRS, DREAM and LAR.

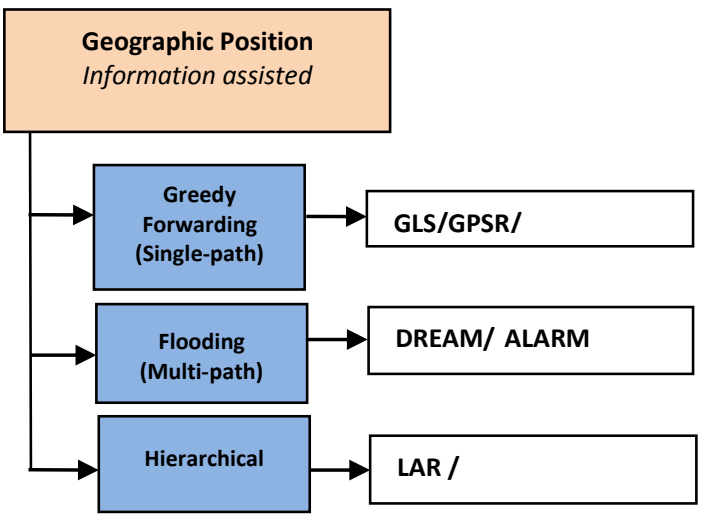

Fig (9) Geographic Position Routing Classification

\subsubsection{Greedy Forwarding (Single-path)}

The shortest path route is an example of a single-path strategy, where one copy of the message is in the network at any time. Most single-path strategies rely on two techniques: greedy forwarding and face routing. Greedy forwarding tries to bring the message closer to the destination in each step using only local information. Greedy forwarding is used when the message is able to advance from source towards the destination (Figure 10-a). It does not imply route establishment or maintenance and the next hop[38].

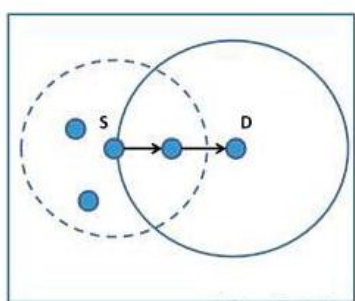

Figure (10) (a) Greedy

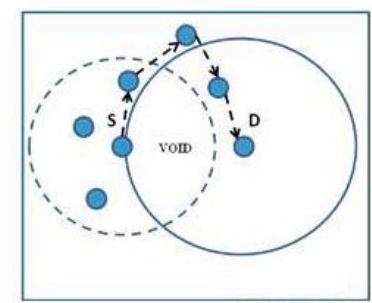

(b) Greedy Failure at node $\mathrm{S}$ 
International Journal of Computer Applications Technology and Research

Volume 6-Issue 3, 141-158, 2017, ISSN:-2319-8656

Table (3) Comparison between the Hierarchical protocols ZHLS, CGSR and LANMAR

\begin{tabular}{|c|c|c|c|}
\hline Properties & ZHLS & CGSR & LANMAR \\
\hline Hierarchical type & Zone Based & Cluster Based & Core Node \\
\hline Advantages & $\begin{array}{l}\text { - The network is geographically } \\
\text { divided into non-overlapping } \\
\text { zones } \\
\text { - ZHLS assumes that each node has } \\
\text { a location system such as GPS and } \\
\text { the geographical information is } \\
\text { well known } \\
\text { - ZHLS defines two levels of } \\
\text { topologies node level and zone } \\
\text { level. } \\
\text { - Single point of failure and } \\
\text { traffic bottlenecks can be } \\
\text { avoided }\end{array}$ & $\begin{array}{l}\text { - Multi-channel routing protocol is } \\
\text { generally used in TDMA or } \\
\text { CDMA-based networks } \\
\text { - Non-uniform hierarchical } \\
\text { protocol } \\
\text { - Forming clusters among nodes } \\
\text { and selecting a cluster head to } \\
\text { control routing to outside the } \\
\text { cluster area. } \\
\text { - Uses a sequence number scheme } \\
\text { to reduce stale routing table } \\
\text { entries and gain loop-free routes. } \\
\text { - Simpler addressing scheme }\end{array}$ & $\begin{array}{l}\text { - Distributive, adaptive, } \\
\text { hierarchical routing } \\
\text { - Robust in rapid topological } \\
\text { change } \\
\text { - Mobile nodes are divided into } \\
\text { predefined logical subnets } \\
\text { according to their mobility } \\
\text { patterns } \\
\text { - Guarantees the shortest path } \\
\text { from a source to a destination if } \\
\text { the destination is located within } \\
\text { the scope of the source. }\end{array}$ \\
\hline Disadvantages & $\begin{array}{l}\text {-ZHLS does not have any cluster } \\
\text { head in the network like other } \\
\text { hierarchical routing protocols } \\
\text { In ZHLS is that all nodes } \\
\text { must have a preprogrammed } \\
\text { static zone map in order to } \\
\text { function or in other words Static } \\
\text { zone map is required }\end{array}$ & $\begin{array}{l}\text { - Highly dynamic environment can } \\
\text { adversely affect protocol } \\
\text { performance } \\
\text { - Frequently changing cluster } \\
\text { heads will have an adverse effect } \\
\text { on the resource allocation } \\
\text { algorithms that depend on it. } \\
\text { - Since additional time is required } \\
\text { to perform cluster head } \\
\text { reselection, time to recover from } \\
\text { link failure is higher than DSDV } \\
\text { and WRP }\end{array}$ & $\begin{array}{l}\text { - LANMAR assumes that nodes are } \\
\text { grouped into subsets according to } \\
\text { their movement patterns and the } \\
\text { membership of each subnet } \\
\text { remains unchanged during the } \\
\text { lifetime of the network, so it is } \\
\text { only suitable for specific } \\
\text { application scenarios } \\
\text { - Assumption of group mobility. } \\
\text { Nodes may not have the best } \\
\text { route to distant destinations }\end{array}$ \\
\hline $\begin{array}{c}\text { Routing } \\
\text { Table/Overhead }\end{array}$ & $\begin{array}{l}\text { - Large communication overhead in } \\
\text { the network, because In ZHLS all } \\
\text { network nodes construct two } \\
\text { routing tables, an intra-zone } \\
\text { routing table and an inter-zone } \\
\text { routing table }\end{array}$ & $\begin{array}{l}\text { - Reduces the size of the routing } \\
\text { table as well as the size of } \\
\text { routing update messages. } \\
\text { - Since each node only maintains } \\
\text { routes to its cluster head in } \\
\text { CGSR, routing overhead is lower } \\
\text { than compared to DSDV and } \\
\text { WRP. }\end{array}$ & $\begin{array}{l}\text { - Reduces both routing table size } \\
\text { and control overhead for large } \\
\text { MANETs. }\end{array}$ \\
\hline Limitations & $\begin{array}{l}\text {-ZHLS take time to search new } \\
\text { route when route is disconnected } \\
\text { because it search only one route. } \\
\text { In particular, real-time application } \\
\text { is severely-impacted by this delay. }\end{array}$ & $\begin{array}{l}\text { - Both cluster member and routing } \\
\text { tables need to be updated } \\
\text { - Uses DSDV as an underlying } \\
\text { routing scheme }\end{array}$ & $\begin{array}{l}\text { - LANMAR is only suitable for } \\
\text { specific mobile applications }\end{array}$ \\
\hline Based algorithm & ZHLS algorithim & $\begin{array}{l}\text { - Clustering algorithm based on the } \\
\text { lowest identifier or the highest } \\
\text { connectivity } \\
\text { - Least Cluster Change (LCC) }\end{array}$ & $\begin{array}{l}\text {-Scoped routing algorithm (e.g., } \\
\text { FSR) } \\
\text { - Binding algorithm }\end{array}$ \\
\hline Cluster structure & $\begin{array}{l}\text { - No masters Multiple gateways } \\
\text { between clusters }\end{array}$ & $\begin{array}{l}\text { - Single gateway } \\
\text { - clustering algorithm based on } \\
\text { the lowest identifier or the } \\
\text { highest connectivity }\end{array}$ & $\begin{array}{l}\text { - Group mobility is assumed so that } \\
\text { relative relationship among } \\
\text { - mobile nodes in a group doesn't } \\
\text { change over time and it results in } \\
\text { a natural clustering. }\end{array}$ \\
\hline Scalability & -Support high scalability & - High scalable. & $\begin{array}{l}\text { - Improves routing scalability for } \\
\text { large MANETs with the } \\
\text { assumption that nodes under a } \\
\text { landmark move in groups. }\end{array}$ \\
\hline
\end{tabular}




\section{Forwarding}

Thus, each node forwards the message to the neighbor that is most suitable from a local point of view. The most suitable neighbor can be the one who minimizes the distance to the destination in each step (Greedy). The decision is made according to the optimization criteria of the algorithm and does not guarantee that a packet reaches its destination. Metrics can be hop count, geographic distance, progress to destination, direction, power, cost, delay, a combination of these, etc. If the message has reached a node which has no closer neighbors to the destination (a void or hole), a recovery procedure is necessary (Figure 10-b) making the forwarding method a hybrid. Recovery from such a concave node can be done through flooding or perimeter (face) forwarding.

\section{Greedy Perimeter Stateless Routing protocol (GPSR)}

(Karp and Kung 2000) proposed GPSR routing protocol which uses the location of node to selectively forward the packets on the basis of distance. The packets are forwarded on a greedy basis by selecting the node closest to the destination. The best path was also calculated through a node which was farther in geometric distance from the destination. This process continues until the destination is reached. In some cases the best path may be through a node which is farther in distance from the destination node. In such scenario right hand rule is applied to forward around the obstacle and resume the greedy forwarding as soon as possible[39, 40].

\subsubsection{Flooding-based (Multi-path)}

In flooding-based approaches, messages are flooded through the whole network area or portion of the area. A simple flooding geocast algorithm works as follows: A node broadcasts a received packet to all neighbors as shown in Fig(11) provided that this packet was not already received before in order to avoid loops and endless flooding. A node delivers a packet if the own location is within the specified destination region, which is included in each geocast packet. This is a simple and robust but not efficient approach, since location information is not used for forwarding in order to reduce the number of packets[41].

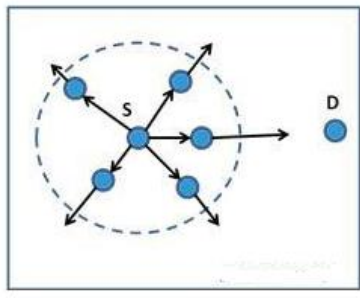

Figure (11) (a) Flooding

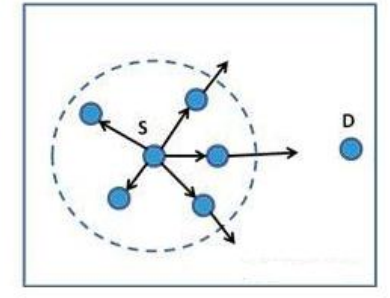

(b) Restricted Flooding

\section{Distance Routing Effect Algorithm for Mobility (DREAM)}

DREAM (Basing et al., 1998) provides location service for position-based routing. In this framework, each node maintains a position database that stores position information about other nodes in the network. It can therefore be classified as an all-forall approach, which means all nodes work as the location service providers, and each node contains all other nodes location information. An entry in the position database includes a node identifier, the direction and distance to the node, together with the time-stamp of entry creation. Each node regularly floods packets to update the position information maintained by the other nodes. Since the accuracy of the position information in the database depends on its age, a node can control the accuracy of its position information available to other nodes by adjusting the frequency of sending.

\subsubsection{Hierarchical Approaches}

The third forwarding strategy is to form a hierarchy in order to scale to a large number of mobile nodes. Some strategies combine the nodes location and hierarchical network structures by using the zone based routing. Others use the dominating set routing. Some others present a two level hierarchy within them; if the destination is close to the sender (in number of hops), packets will be routed based on a proactive distance vector. Greedy routing is used in long distance routing[39].

\section{Location Aided Routing (LAR):}

(Ko and Vaidya 1998, Ljubica Blazevie et al 2005) presents the LAR protocol which utilizes location information to minimize the search space for route discovery towards the destination node [39]. LAR is a reactive unicast routing protocol which based on DSR. LAR aims to reduce the routing overhead for the route discovery and it uses the Global Positioning System (GPS) to obtain the location information of a node. LAR essentially describes how location information such as GPS can be used to reduce the routing overhead in an ad hoc network and ensure maximum connectivity. Location-Aided Routing is an example of restricted directional flooding routing protocols; however, partial flooding is used in LAR for path discovery purpose. Hence, LAR proposes the use of position information to enhance the route discovery phase of reactive Ad-Hoc routing approaches. Table (4) contain a comparison between a three geographic Position protocols GPRS, DREAM and LAR.

\subsection{Power Aware routing protocols}

As MANET lack of fixed infrastructure and mobiles nodes in MANET are battery driven, in such environment energy efficiency is an important consideration to increase the network[42] .Since the nodes in MANETs are mobile, the routing and power management become critical issue[43] .Several power aware routing schemes have been proposed for MANETs networks $\operatorname{Fig}(12)$. The main objective of power aware routing scheme is to minimize the power consumption and maximize the network lifetime. The network lifetime is defined up to the moment when a node runs out of its own battery power for the first time[44].This classification of protocols is based on the consumption of energy during transmission. I.e., Energy required to transmit a signal is approximately proportional to $d X$, where $d$ is distance and is the attenuation factor or path loss exponent, which depends on transmission medium. When $\mathrm{X}=2$, which is optimal case, Transmitting a signal half of the distance required one fourth of energy and if anode is in the middle, will spend another fourth of energy for the second half. Thus data will transmit for half of the energy than through direct transmission.

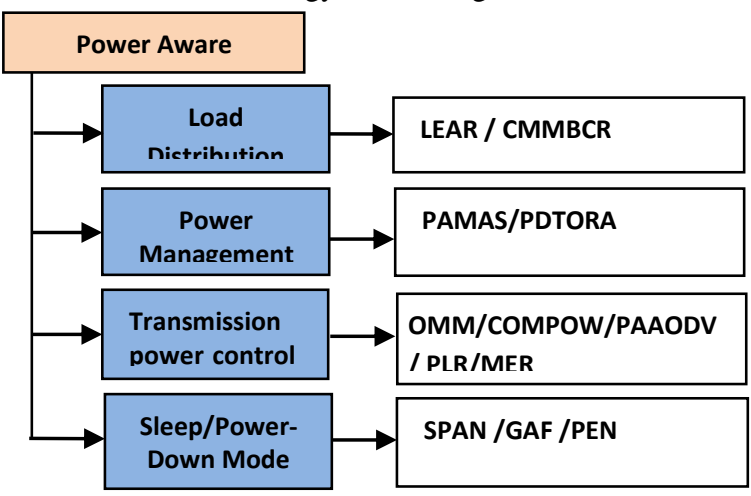

Figure (12) Power and Energy-aware subdivisions 
Table (4) Comparison of Geo-protocols GPSR ,DREAM and LAR

\begin{tabular}{|c|c|c|c|}
\hline col & GPSR & DREAM & LAR \\
\hline $\begin{array}{c}\text { Geographic } \\
\text { Position } \\
\text { Type }\end{array}$ & $\begin{array}{c}\text { Greedy } \\
\text { Forwarding }\end{array}$ & Flooding & Hierarchical \\
\hline Advantages & $\begin{array}{l}\text {-Guarantees a } \\
\text { good PDR } \\
\text { especially in the } \\
\text { high density of } \\
\text { nodes, } \\
\text {-Data } \\
\text { forwarding } \\
\text { overhead is low } \\
\text {-Increasing of } \\
\text { efficiency when } \\
\text { more node } \\
\text { added to the } \\
\text { network } \\
\text { - local maxima } \\
\text { can be found } \\
\text { easily }\end{array}$ & $\begin{array}{l}\text { Packet loss is } \\
\text { higher than } \\
\text { GPSR } \\
\text { - No delay for } \\
\text { routing } \\
\text { discovery } \\
\text { methods }\end{array}$ & $\begin{array}{l}\text {-Localized route } \\
\text { discover } \\
\text { - Restricted } \\
\text { directional flooding } \\
\text {-Reduces routing } \\
\text { overhead } \\
\text {-Reduce the number } \\
\text { of nodes to which } \\
\text { the route request is } \\
\text { propagated. }\end{array}$ \\
\hline Disadvantages & $\begin{array}{l}\text {-impossible to } \\
\text { find the optimal } \\
\text { path } \\
\text {-Scalability } \\
\text { occurs when } \\
\text { increasing in } \\
\text { network } \\
\text { diameter and } \\
\text { mobility } \\
\text {-Delay increases } \\
\text { at high mobility, } \\
\text {-generates a } \\
\text { large number of } \\
\text { control packets } \\
\text { for high speeds }\end{array}$ & $\begin{array}{l}\text { Requires GPS. } \\
\text { Flooding, can } \\
\text { influence the } \\
\text { performance of } \\
\text { the basic } \\
\text { algorithm. } \\
\text { A recovery } \\
\text { method is } \\
\text { necessary when } \\
\text { the destination } \\
\text { node is not in } \\
\text { the given } \\
\text { direction. }\end{array}$ & $\begin{array}{l}\text {-Based on source } \\
\text { routing, flooding } \\
\text { is used if no location } \\
\text { information is } \\
\text { available } \\
\text {-Low performance } \\
\text { when various } \\
\text { optimization } \\
\text { techniques are not } \\
\text { implemented like } \\
\text { alternative definition } \\
\text { of request zone, } \\
\text { another adaptation } \\
\text { of request zone, and } \\
\text { so on }\end{array}$ \\
\hline $\begin{array}{c}\text { Energy } \\
\text { consumption }\end{array}$ & Low & High & High \\
\hline $\begin{array}{c}\text { Routing } \\
\text { metric }\end{array}$ & Closest distance & Shortest Path & Shortest Path \\
\hline $\begin{array}{c}\text { Packet } \\
\text { Delivery } \\
\text { Ratio(PDR), }\end{array}$ & High & Low & Low \\
\hline $\begin{array}{l}\text { Jitter and end } \\
\text { to end delay }\end{array}$ & Lower delay & Long delay & Long delay \\
\hline $\begin{array}{c}\text { Routing/Com } \\
\text { munication } \\
\text { Overhead }\end{array}$ & -High & $\begin{array}{l}\text {-minimizes } \\
\text { routing overhead }\end{array}$ & $\begin{array}{l}\text { reduces overhead by } \\
\text { limiting search to } \\
\text { requested zone only, } \\
\text { reduce traffic, no need } \\
\text { of hello message }\end{array}$ \\
\hline
\end{tabular}

\subsubsection{Load Distribution}

This approach is also based on active communication energy. The main goal of this approach is to balance the amount of energy usage among all mobile nodes and to maximize the lifetime of network by avoiding over-utilized nodes when selecting a routing path. The protocol selecting underutilized nodes rather than the shortest route. This may result in longer routes, but packets are routed only through energy rich intermediate nodes. Protocols based on this approach do not only provide route with lowest energy, but prevent certain nodes from being overloaded, and thus increases the network lifetime. The most popular examples of this approach is Localized Energy-Aware Routing (LEAR), Conditional Max-Min Battery Capacity Routing protocols (CMMBCR).

\section{Localized Energy-Aware Routing (LEAR)}

The LEAR (Woo et al. 2001) protocol directly controls the energy consumption. In particular, it achieves balanced energy consumption among all participating mobile nodes. The LEAR protocol is based on DSR, where the route discovery requires flooding of route-request messages. When a routing path is searched, each mobile node relies on local information of remaining battery level to decide whether or not to participate in the selection process of a routing path. An energy-hungry node can conserve its battery power by not forwarding data packets on behalf of others. Decision -making process in LEAR is distributed to all relevant nodes, and the destination node does not need wait or block it order to find the most energy efficient path. Upon receiving a route -request message, each mobile node has the choice to determine whether or not to accept and forward the route -request message depending on its remaining battery power $\left(\boldsymbol{E}_{r}\right)$. When it is higher than a threshold value $\left(\boldsymbol{T} \boldsymbol{h}_{\boldsymbol{r}}\right)$, the routerequest message is forwarded; otherwise, the message is dropped. The destination will receive a route-request message only when all intermediate nodes along the route have good battery levels. Thus, the first arriving message is considered to follow an energy-efficient as well as a reasonably short path.

\subsubsection{Power Management}

Power management technique is used to reduce the energy consumed in the MANETs interface of battery powered mobile devices. The design of best possible power management policies needs to explicitly account for the dissimilar performance requirements posed by different application scenarios such as latency, throughput and other performance metrics[43]. Power management techniques have been studied comprehensively in the context of CPU, memory and disk management in the past. The main idea is to switch devices to the low-power state in periods of inactivity. As compared with traditional techniques in operating systems, power management in communication devices requires distributed coordination between two (or multiple) communicating entities, as all the entities have to be in the active mode for a successful communication.

Power Aware Multi-Access (PAMAS) routing protocol :PAMAS is an extension to the AODV protocol. It uses a new routing cost model to discourage the use of nodes running low on battery power. The lifetime of the network is improved significantly. This routing protocol saves energy by turning off radios when the nodes are not in use. Although, it was implemented on the AODV protocol, the technique used is very standard and can be used with any on-demand protocol. The energy aware protocol works only in the routing layer. Advantage of PAMAS protocol is that this protocol saves $40-70 \%$ of battery power by intelligently turning off radios when they cannot transmit or cannot receive packets. This protocol tends to increase the throughput of the network as compared to other power aware routing protocols .One of the disadvantages of PAMAS protocol is broadcasting problem. In this protocol, a broadcast may collide with another transmission at some receiver[42].

\subsubsection{Transmission power control}

Transmission power control approach can be achieved with the help of topology control of a MANET [23]. The transmission power determines the range over which the signal can be coherently received, and is therefore crucial in determining the performance of the network (throughput, delay, and power consumption) [24]. Power aware routing protocols based on transmission power control finds the best route that minimizes the total transmission power between a source and destination. It is equivalent to a graph optimization problem, where each link is weighted with the link cost corresponding to the required transmission power. Finding the most power efficient (min-power) route from source to destination is 
equivalent to finding the least cost path in the weighted graph. A routing algorithm essentially involves finding an optimal route on a given network graph where a vertex represents a mobile node and an edge represents a wireless link between two end nodes that are within each other's radio transmission range. In this paper, we reviewed various power aware routing protocols explained each one of them by taking our own examples and also introduced the new power aware routing protocol i.e. PADSR.

\section{Online Max-Min Routing Protocol (OMM)}

Online Max-Min (OMM) power-aware routing protocol for MANETs networks dispersed over large geographical areas to support applications where the message sequence is not known. This protocol uses two different metrics of the nodes in the network to optimizes the lifetime of the network as well as the lifetime of individual nodes by maximizing the minimal residual power (max-min), which helps to prevent the occurrence of overloaded nodes, the other metric is Minimizing power consumption (min-power) . In most applications that involve MANETs, power management is a real challenge and can be done at two complementary levels (1) during communication and (2) during idle time. The OMM protocol maximizes the lifetime of the network without knowing the data generation rate in advance. The metrics developed showed that OMM had a good empirical competitive ratio to the optimal online algorithm that knows the message sequence and the max-min achieves over $80 \%$ of the optimal node lifetime for most instances and over $90 \%$ of the optimal node lifetime for many problem instances. OMM protocol uses Dijkstra's algorithm to find the optimal path between source-destination pair. This min-power path consumes the minimal power ( $\mathrm{P}$ min ).In order to optimize the second metric, the OMM protocol obtains multiple near-optimal minpower paths that do not deviate much from the optimal value (i.e., less than $z P \min$ where $z \geq 1)$ and selects the best path that optimizes the max-min metric. Figure-(13) shows an example of the algorithm for a given source and destination pair. In Figure-3 (a), $\mathrm{S} \rightarrow B \rightarrow D$ is the min-power path as it consumes the minimal energy $(\mathrm{P} \min =22)$ i.e. path $\cos$ is 22 . If $\mathrm{z}=2$, alternative paths $\mathrm{S} \rightarrow A \rightarrow D$ (path cost=27) and $\mathrm{S} \rightarrow C \rightarrow D$ (path cost $=28$ ) can be considered since their path costs are within the tolerance range $(z P \min =44)[45,46]$.

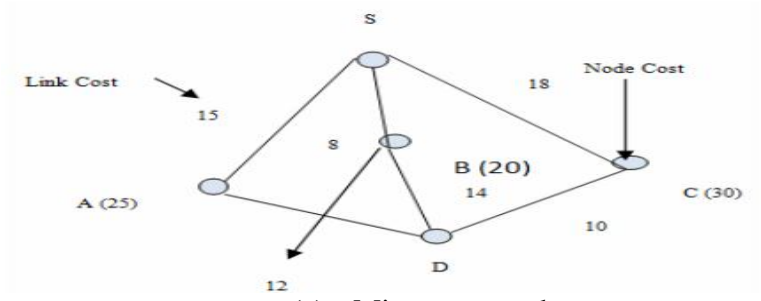

(a) Min-power path

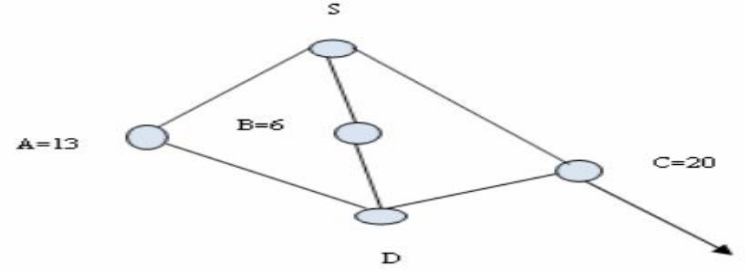

(b) Max-min path

Figure (13) Min-power path and max-min path in the OMM protocol [44]

3.4.4 Sleep/Power-Down Mode
This approach is based on saving the energy during inactivity means when node is idle. Nodes can save the energy during inactivity by switching into sleep/power-down mode when there is no data to transmit or receive. This leads to considerable energy savings, especially when the network environment is characterized with low duty cycle of communication activities. However, it requires well-designed routing protocol to guarantee data delivery even if most of the nodes sleep and do not forward packets for other nodes.

\section{SPAN protocol}

SPAN protocol is a power saving mechanism that reduces power consumption of nodes by retaining the capacity and coordinating with the underlying MAC layer[47]. SPAN protocol operates between the routing layer and the MAC layer. SPAN coordinates the "stay-awake and sleep" cycle of the nodes and also performs multi-hop packet routing within the ad hoc network. While other nodes remain in the power saving mode and periodically check if they should remain awaken and become a coordinator. SPAN adaptively elects coordinators by allowing each node to use a random back-off delay to decide whether to become a coordinator in the network and rotates them in time. This technique not only preserves network connectivity, it also preserves capacity, decreases latency and provides significant energy saving. Other advantage of the SPAN protocol is that the master nodes play an important role in routing by providing a routing backbone and control traffic as well as channel contention is reduced. Disadvantage of SPAN protocol is that the amount of power saving increases slightly as density decreases.

\subsection{Multicast Routing Protocols}

Multicast is the delivery of information to a group of destinations simultaneously, using the most efficient strategy to deliver the messages over each link of the network only once, creating copies only when the links to the destinations split. Multicast routing protocols for MANET use both multicast and unicast for data transmission[29].In recent years, a number of multicast protocols for ad hoc networks have been proposed. Based on the routing structure, they can broadly be classified into two categories: treebased protocols and mesh-based protocols [48].Fig (14) below shown the basic subdivisions of the Multicast routing protocols .

3.5.1 Tree Based Multicast Routing Protocols: In tree-based protocols, there exists a single path between any sender-receiver pair. Tree-based protocols have the advantage of high multicast efficiency (which is defined as the ratio of the total number of data packets received by all receivers to the total number of data packets transmitted or retransmitted by senders or intermediate nodes). However, tree-based protocols are not robust against frequent topology changes and the packet delivery ratio (which is defined as the ratio of the number of data packets delivered to all receivers to the number of data packets supposed to be received by all receivers) drops at high mobility.

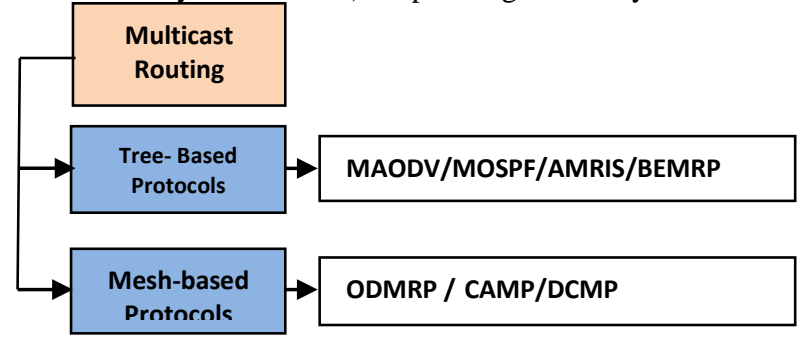

Figure (14) Multicast Routing Protocols subdivisions based on the Network structure 
International Journal of Computer Applications Technology and Research

Volume 6-Issue 3, 141-158, 2017, ISSN:-2319-8656

Table (5) Comparison among different MANETs routing approach[50]

\begin{tabular}{|c|c|c|c|c|c|c|}
\hline Protocol & $\begin{array}{c}\text { Structure /Route } \\
\text { Computation }\end{array}$ & \#Routes & Stored Information & $\begin{array}{l}\text { Update } \\
\text { Period }\end{array}$ & $\begin{array}{c}\text { Update } \\
\text { information }\end{array}$ & $\begin{array}{l}\text { Update } \\
\text { Dest. }\end{array}$ \\
\hline \multicolumn{7}{|c|}{ Flat Routing (Topology Based) ---- Reactive (On-Demand) } \\
\hline AODV & $\begin{array}{l}\text { Flat-Reactive/ } \\
\text { broadcast QUERY }\end{array}$ & Multiple & Next hops for desired dest. & $\begin{array}{l}\text { Event- } \\
\text { driven RM }\end{array}$ & ROUTE-ERROR & Source \\
\hline TORA & $\begin{array}{c}\text { Flat-Reactive/ } \\
\text { broadcast QUERY }\end{array}$ & Multiple(DAG) & Neighbors' heights & $\begin{array}{l}\text { Event- } \\
\text { driven }\end{array}$ & Node's height & Neighbors \\
\hline AQOR & $\begin{array}{c}\text { Flat-Reactive/ } \\
\text { Limited QUERY }\end{array}$ & Multiple & $\begin{array}{l}\text { bandwidth and end to-end } \\
\text { delay }\end{array}$ & Periodical & $\begin{array}{l}\text { bandwidth ,end to- } \\
\text { end delay, signaling }\end{array}$ & Neighbors \\
\hline DSR & $\begin{array}{c}\text { Flat-Reactive/ } \\
\text { broadcast QUERY }\end{array}$ & Multiple & Routes to desired Dest. & $\begin{array}{c}\text { Event- } \\
\text { driven RM }\end{array}$ & ROUTE-ERROR & Source \\
\hline \multicolumn{7}{|c|}{ Flat Routing (Topology Based) --- Proactive (Table Driven) } \\
\hline OLSR & $\begin{array}{l}\text { Flat-Proactive/ } \\
\text { distributed }\end{array}$ & Multiple & $\begin{array}{l}\text { MPR nodes, link load, } \\
\text { delay, bandwidth }\end{array}$ & Periodical & $\begin{array}{l}\text { HELLO and TC } \\
\text { messages }\end{array}$ & Neighbors \\
\hline DSDV & $\begin{array}{c}\text { Flat-Proactive/ } \\
\text { distributed }\end{array}$ & Single & Distance vector & Hybrid & Distance vector & Neighbors \\
\hline FSR & $\begin{array}{l}\text { Flat-Proactive/ } \\
\text { distributed }\end{array}$ & $\begin{array}{l}\text { Single or } \\
\text { multiple }\end{array}$ & $\begin{array}{c}\text { Entire topology, closer } \\
\text { nodes }\end{array}$ & $\begin{array}{l}\text { Periodicals( } \\
\text { dif. freq.) }\end{array}$ & $\begin{array}{l}\text { Link state of fisheye } \\
\text { scope, distant nodes }\end{array}$ & Neighbors \\
\hline WRP & $\begin{array}{c}\text { Flat-Proactive/ } \\
\text { distributed }\end{array}$ & Single & $\begin{array}{c}\text { Dist./routing/link-cost } \\
\text { table, MRL }\end{array}$ & Hybrid & Dist. Vec., List of Resp. & Neighbors \\
\hline GSR & $\begin{array}{l}\text { Flat-Proactive/ } \\
\text { distributed }\end{array}$ & $\begin{array}{l}\text { Single or } \\
\text { multiple }\end{array}$ & Entire topology & Periodical & All nodes link state & Neighbors \\
\hline \multicolumn{7}{|c|}{ Flat- Routing --- Hybrid routing Protocols } \\
\hline ZRP & $\begin{array}{c}\text { Flat-Hybrid } \\
\begin{array}{c}\text { Proactive(intra)/Reac } \\
\text { tive(inter) }\end{array} \\
\end{array}$ & $\begin{array}{l}\text { Single or } \\
\text { multiple }\end{array}$ & $\begin{array}{l}\text { Local (within zone), } \\
\text { topology }\end{array}$ & Periodical & $\begin{array}{l}\text { Link state of nodes in } \\
\text { the zone }\end{array}$ & Neighbors \\
\hline ZHLS & $\begin{array}{c}\text { Hierarchy-Hybrid/ } \\
\text { Proactive/Reactive } \\
\text { (hier. addr.) }\end{array}$ & Multiple & $\begin{array}{l}\text { Local(inter zone), (intra } \\
\text { zone) topology }\end{array}$ & $\begin{array}{l}\text { Period./Eve } \\
\text { nt-driven }\end{array}$ & Node/Zone, link state & $\begin{array}{c}\text { Zone/all } \\
\text { nodes }\end{array}$ \\
\hline \multicolumn{7}{|c|}{ Hierarchical protocols } \\
\hline CSGR & \begin{tabular}{|c|} 
Hierarchy-cluster- \\
Proactive/ distributed
\end{tabular} & Single & $\begin{array}{c}\text { Cluster. Member. Table, } \\
\text { Dist.Vec. }\end{array}$ & Periodical & $\begin{array}{l}\text { Cluster. Member. } \\
\text { Table, Dist.Vec. }\end{array}$ & $\begin{array}{l}\text { Neigh.\&Clus. } \\
\text { head }\end{array}$ \\
\hline LANMAR & Hierarchy-Core node & $\begin{array}{l}\text { Single or } \\
\text { multiple }\end{array}$ & $\begin{array}{l}\text { Entire topology, dist.Vec. } \\
\text { of landmark nodes. }\end{array}$ & Periodical & $\begin{array}{c}\text { landmark distance } \\
\text { vector, Next Hop } \\
\text { Address, sender's LMDV }\end{array}$ & $\begin{array}{c}\text { Next Hop } \\
\text { /Destination }\end{array}$ \\
\hline CEDAR & $\begin{array}{c}\text { Hierarchy-Proactive/ } \\
\text { core broadcast QUERY }\end{array}$ & Single & $\begin{array}{l}\text { Core/other nodes: } \\
\text { global/local }\end{array}$ & $\begin{array}{c}\text { Period./Eve } \\
\text { nt-driven }\end{array}$ & $\begin{array}{l}\text { Dynamic/stable } \\
\text { Link state }\end{array}$ & $\begin{array}{c}\text { Neigh./Core } \\
\text { nodes }\end{array}$ \\
\hline \multicolumn{7}{|c|}{ Geographic Position (Information assisted) Routing Protocols } \\
\hline GPSR & $\begin{array}{l}\text { Geographic- Greedy } \\
\text { Forwarding/ }\end{array}$ & Single & $\begin{array}{c}\text { Greedy mode( provides all } \\
\text { nodes with their } \\
\text { neighbors' positions) }\end{array}$ & $\begin{array}{c}\text { Periodic } \\
\text { beaconing }\end{array}$ & $\begin{array}{l}\text { Perimeter mode } \\
\text { (Beacon to the } \\
\text { broadcast MAC } \\
\text { address, IP, position.) }\end{array}$ & $\begin{array}{c}\text { greedily } \\
\text { /neighbors }\end{array}$ \\
\hline DREAM & $\begin{array}{c}\text { Geographic-flooding } \\
\text { / distributed }\end{array}$ & Multiple & $\begin{array}{l}\text { position info., about other } \\
\text { nodes in the network }\end{array}$ & Periodical & $\begin{array}{c}\text { distances separating } \\
\text { nodes }\end{array}$ & $\begin{array}{c}\text { Dest., node, } \\
\text { neighbor node. }\end{array}$ \\
\hline LAR & $\begin{array}{l}\text { Geographic- } \\
\text { reactive }\end{array}$ & multiple & $\begin{array}{c}\text { Location of the } \\
\text { destination, distance to } \\
\text { define the requested zone. }\end{array}$ & $\begin{array}{l}\text { periodic } \\
\text { update of } \\
\text { beacons }\end{array}$ & $\begin{array}{l}\text { expected zone of the } \\
\text { destination }\end{array}$ & request zone \\
\hline \multicolumn{7}{|c|}{ Power-Aware, Energy-Efficiency routing Protocols } \\
\hline LEAR & Power-aware & multiple & $\begin{array}{l}\text { Battery Power }\left(\mathrm{E}_{\mathrm{r}}\right) \text { and } \\
\text { threshold value }\left(\mathrm{Th}_{r}\right)\end{array}$ & Periodical & $\begin{array}{l}\text { energy efficient, } \\
\text { shortest path }\end{array}$ & Destination \\
\hline PAMAS & $\begin{array}{c}\text { Power-aware/ RTS-CTS } \\
\text { message exchange }\end{array}$ & multiple & $\begin{array}{c}\text { Await Packet, Idle, wait CTS, } \\
\text { BEB }\end{array}$ & Periodical & CTS or Busy Tone & Neighbors \\
\hline SPAN & $\begin{array}{c}\text { Power-aware/ } \\
\text { broadcast QUERY }\end{array}$ & multiple & $\begin{array}{l}\text { routing backbone and } \\
\text { control traffic }\end{array}$ & Periodical & & Neighbors \\
\hline OMM & $\begin{array}{l}\text { Power-aware/ Min- } \\
\text { power , and max-min }\end{array}$ & multiple & $\begin{array}{l}\text { Link cost, Node cost, } \\
\text { tolerance range, graph } \\
\text { optimization algorithm }\end{array}$ & Periodical & $\begin{array}{c}\mathrm{zP \operatorname {min }}, \mathrm{P}_{\min }, \text { link } \\
\text { costs }\end{array}$ & $\begin{array}{c}\text { Dest., } \\
\text { Neighbors }\end{array}$ \\
\hline \multicolumn{7}{|c|}{ Multicast Routing Protocols } \\
\hline MAODV & Multicast & Multiple & $\begin{array}{l}\text { requesting node's, next } \\
\text { hop }\end{array}$ & periodically & RREP, forward path & next hop \\
\hline ODMRP & Multicast & Multiple & $\begin{array}{c}\text { source ID , sequence number } \\
\text { in its message cache }\end{array}$ & periodically & $\begin{array}{l}\text { group membership } \\
\text { and multicast routes }\end{array}$ & Neighbors \\
\hline
\end{tabular}

www.ijcat.com 


\section{Multicast Ad Hoc On-Demand Distance Vector Routing Protocol (MAODV)}

(Elizabeth Royer and Perkins 1999) proposed MAODV routing protocol [49] witch discovers multicast routes on demand using a broadcast route-discovery mechanism. A mobile node originates a Route Request (RREQ) message when it wishes to join a multicast group, or when it has data to send to a multicast group but it does not have a route to that group. Only a member of the desired multicast group may respond to a join RREQ. If the RREQ is not a join request, any node with a fresh enough route (based on group sequence number) to the multicast group may respond. If an intermediate node receives a join RREQ for a multicast group of which it is not a member, or if it receives a RREQ and it does not have a route to that group, it rebroadcasts the RREQ to its neighbors. As the RREQ is broadcast across the network, nodes set up pointers to establish the reverse route in their route tables. A node receiving a RREQ first updates its route table to record the sequence number and the next hop information for the source node. This reverse route entry may later be used to relay a response back to the source. For join RREQs, an additional entry is added to the multicast route table. This entry is not activated unless the route is selected to be part of the multicast tree. If a node receives a join RREQ for a multicast group, it may reply if it is a member for the multicast group's tree and its recorded sequence number for the multicast group is at least as great as that contained in the RREQ. The responding node updates its route and multicast route tables by placing the requesting node's next hop information in the tables, and then unicasts a Request Response (RREP) back to the source node. As nodes along the path to the source node receive the RREP, they add both a route table and a multicast route table entry for the node from which they received the RREP, thereby creating the forward path, see Figure 15.

3.5.2 Mesh-based protocols provide redundant routes for maintaining connectivity to group members. The low alleviated due to redundant routes. Mesh-based protocols are robust to node mobility. However, redundant routes cause low multicast efficiency.

On-demand Multicast Routing Protocol (ODMRP) ODMRP (On-demand Multicast Routing Protocol) [51]is mesh based, and uses a forwarding group concept (only a subset of nodes forwards the multicast packets). A soft-state approach is taken in ODMRP to maintain multicast group members. No explicit control message is required to leave the group. In ODMRP, group membership and multicast routes are established and updated by the source on demand. When a multicast source has packets to send, but no route to the multicast group, it broadcasts a Join-Query control packet to the entire network. This Join-Query packet is periodically broadcast to refresh the membership information and update routes, see Figure 2.

When an intermediate node receives the Join-Query packet, it stores the source ID and the sequence number in its message cache to detect any potential duplicates. The routing table is updated with the appropriate node ID (i.e. backward learning) from which the message was received for the reverse path back to the source node. If the message is not a duplicate and the TimeTo-Live (TTL) is greater than zero, it is rebroadcast. When the Join-Query packet reaches a multicast receiver, it creates and broadcasts a "Join Reply" to its neighbors. When a node receives a Join Reply, it checks if the next hop node ID of one of the entries matches its own ID. If it does, the node realizes that it is on the path to the source and thus is part of the forwarding group and sets the FG_FLAG (Forwarding Group Flag).It then broadcasts its own Join Table built upon matched entries. The next hop node ID field is filled by extracting information from its routing table. In this way, each forward group member propagates the Join Reply until it reaches the multicast source via the selected path (shortest). This whole process constructs (or updates) the routes from sources to receivers and builds a mesh of nodes, the forwarding group.

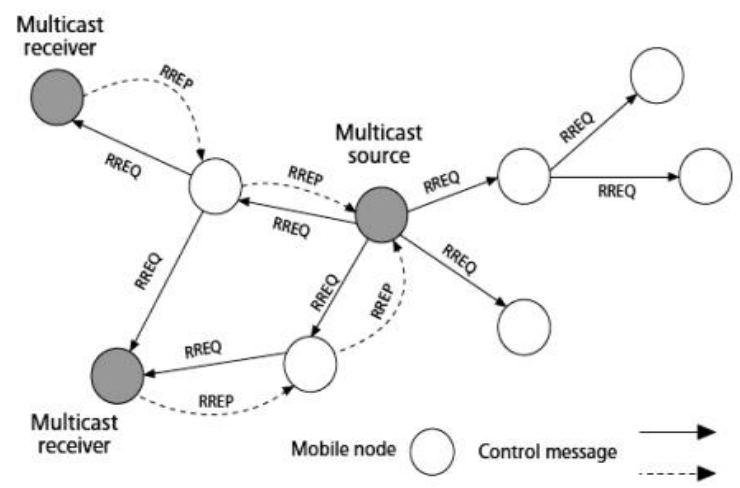

Fig (15) MOADV route discovery mechanism[52]

\section{IV.CONCLUSION AND FUTURE WORKS}

This paper presents a comprehensive survey and overview of the recent routing process and strategies of MANETs. In the literature most of the authors classified MANETs routing protocols into: proactive, reactive and hybrid. However this classification is not covering other important routing mechanisms in MANETs such as Hierarchical Routing (HR), Geographical Routing (GR), Power Aware (PA) and Multicast Routing (MR). In this paper, several existing routing protocols for MANETs networks were described. One example for each category of routing strategy was discussed. While this survey we found that AODV, OLSR and TORA from the Flat-routing approach are powerful, highly adaptive, efficient and scalable distributed routing algorithm. Those protocols are efficient and adaptable for different application specifically real time applications such as video streaming or video conferencing. From the Hierarchical approach we found that ZHLS, LANMAR and CGSR are highly scalable and in the other hand has least communication overhead, means that these protocols are capable for delay sensitive applications and also compatible for tactical scenarios where the nodes are spread out a huge coverage area. The Geographic routing protocols such as (GPSR, DREAM and LAR) scale better for MANETs mainly for two reasons: 1) there is no necessity to keep routing tables up-to-date and 2) no need to have a global view of the network topology and its changes. The power aware and multicast routing provides a low communication overhead and it benefits in large scale MANETs and it will be feasible for some applications such as VANET, iMANET, smart cities and IoT.

\section{REFERENCES}

[1] M. K. Nazir, Rehman, R.U. and Nazir, A., "A Novel Review on Security and Routing Protocols in MANET," Communications and Network, vol. 8, pp. $205-218,2016$.

[2] S. R. Inamdar and R. M. Yadahalli, "Paradigm Shift in Routing Approaches for High Speed MANET Applications," European Journal of Engineering Research and Science, vol. 2, 2017.

[3] D. S. R. M.Vijayalakshmi, "EFFICIENT MULTICAST ROUTING PROTOCOL FOR MANETS," 
International Journal of Computer Applications Technology and Research

Volume 6-Issue 3, 141-158, 2017, ISSN:-2319-8656

International Journal of Computer Networks and Wireless Communications (IJCNWC),, vol. 6, pp. 56 61, 2016.

[4] Bharathi, "A Review and Comparative Study on Various Routing Protocols for MANET," International Journal of Innovative Research in Science,Engineering and Technology, vol. 5, pp. 20790 - 20795, 2016.

[5] R. Suma and B. Premasudha, "Geographical routing protocols for mobile ad hoc networks-a survey on their performance analysis," International Journal of Research in Engineering and Technology eISSN, pp. 2319-1163, 2013.

[6] B. A. Mahmood and D. Manivannan, "Position based and hybrid routing protocols for mobile ad hoc networks: a survey," Wireless Personal Communications, vol. 83, pp. 1009-1033, 2015.

[7] D. Muhit, "Performance Evaluation Of Aodv, Dsr, Dsdv Mobile Ad-Hoc Protocols On Different Scenarios: An Analytical Review," International Journal of Advances in Computing and Information Technology, 2012.

[8] B. Jagdale, P. Patil, P. Lahane, and D. Javale, "Analysis and Comparison of Distance Vector, DSDV and AODV Protocol of MANET," International Journal of Distributed and Parallel Systems, vol. 3, p. 121, 2012.

[9] Y. Lu, W. Wang, Y. Zhong, and B. Bhargava, "Study of distance vector routing protocols for mobile ad hoc networks," in Pervasive Computing and Communications, 2003.(PerCom 2003). Proceedings of the First IEEE International Conference on, 2003, pp. 187-194.

[10] K. Gorantala, "Routing protocols in mobile ad-hoc networks," A Master'thesis in computer science, pp-136, 2006.

[11] A. Boukerche, Handbook of algorithms for wireless networking and mobile computing: CRC Press, 2005.

[12] S. Mohapatra and P. Kanungo, "Performance analysis of AODV, DSR, OLSR and DSDV routing protocols using NS2 Simulator," Procedia Engineering, vol. 30, pp. 69-76, 2012.

[13] S. Ade and P. Tijare, "Performance comparison of AODV, DSDV, OLSR and DSR routing protocols in mobile ad hoc networks," International Journal of Information Technology and Knowledge Management, vol. 2, pp. 545-548, 2010.

[14] D. S. P. a. D. K. K. SANJEEV GANGWAR, "Mobile Ad Hoc Networks: A Comparative Study of QoS Routing Protocols " IJCSET, vol. 2, pp. 771-775, 2012.

[15] S. Gangwar and K. Kumar, "Mobile Ad Hoc Networks: A detailed Survey of QoS Routing Protocols," International Journal of Distributed and Parallel Systems (IJDPS) Vol, vol. 2, 2011.

[16] R. Sivakumar, P. Sinha, and V. Bharghavan, "CEDAR: a core-extraction distributed ad hoc routing algorithm," IEEE Journal on Selected Areas in Communications, vol. 17, pp. 1454-1465, 1999.

[17] T. Kilinkaridis, "Routing Protocols for Wireless Ad Hoc Networks."

[18] S. Raja and K. Alagarsamy, "ROUTING PROTOCOLS IN MANET QOS SURVEY," International Journal of Innovative Research in Advanced Engineering (IJIRAE), vol. 2, pp. 169 - 157, 2015.
[19] X. Wang, "Mobile Ad-Hoc Networks: Protocol Design," 2011.

[20] R. K. P. Behra Rajesh Umashankar, "A Comparative Study of Topology and Position Based Routing Protocols in Mobile Ad Hoc Networks," International Journal of Advanced Research in Computer Science \& Technology (IJARCST ), vol. 2, pp. 72 - 75, 2014.

[21] M. B. Banu and P. Periyasamy, "A Survey of Unipath Routing Protocols for Mobile Ad Hoc Networks," International Journal of Information Technology and Computer Science (IJITCS), vol. 6, p. 57, 2013.

[22] V. Deepalakshmi, T. Muthuramalingam, and M. R. Vijayalakshmi, "Current Survey of Routing Protocols in MANETS," in International Journal of Engineering Research and Technology, 2014.

[23] B. Kukreja and S. Kambhra, "Performance Comparison of Routing Protocols in MANET," International Journal of Computer Science and Network Security (IJCSNS), vol. 14, p. 108, 2014.

[24] N. Zhang and A. Anpalagan, "Comparative review of QoS-aware on-demand routing in ad hoc wireless networks," Wireless Sensor Network, vol. 2, p. 274, 2010.

[25] N. Beijar, "Zone routing protocol (ZRP)," Networking Laboratory, Helsinki University of Technology, Finland, pp. 1-12, 2002.

[26] S. Goyal, "ZONE ROUTING PROTOCOL (ZRP) IN AD-HOC NETWORKS," vol. 3, ed: IJREAS, 2013.

[27] S. K. Sarkar, T. Basavaraju, and C. Puttamadappa, Ad hoc mobile wireless networks: principles, protocols and applications: CRC Press, 2007.

[28] N. H. Saeed, M. F. Abbod, and H. S. Al-Raweshidy, "MANET routing protocols taxonomy," in Future Communication Networks (ICFCN), 2012 International Conference on, 2012, pp. 123-128.

[29] G. V. Kumar, Y. V. Reddyr, and D. M. Nagendra, "Current research work on routing protocols for MANET: a literature survey," international Journal on computer Science and Engineering, vol. 2, pp. 706-713, 2010.

[30] M. Rezaee and M. Yaghmaee, "Cluster based routing protocol for mobile ad hoc networks," INFOCOMP Journal of Computer Science, vol. 8, pp. 30-36, 2009.

[31] B. Lee, C. Yu, and S. Moh, "Issues in scalable clustered network architecture for mobile ad hoc networks," Handbook of Mobile Computing, pp. 1-27, 2004.

[32] C.-C. Chiang, H.-K. Wu, W. Liu, and M. Gerla, "Routing in clustered multihop, mobile wireless networks with fading channel," in proceedings of IEEE SICON, 1997, pp. 197-211.

[33] M. M. Artimy, W. Robertson, and W. J. Phillips, "Algorithms and Protocols for Wireless and Mobile Ad Hoc Networks," ed: John Wiley \& Sons, 2009.

[34] M. C. STEFANO BASAGNI , SILVIA GIORDANO , IVAN STOJMENOVIC, Mobile ad hoc networking: John Wiley \& Sons, 2004.

[35] D. Pramanik, "Classification of Ad Hoc Routing Protocols," International Journal of Innovative Technology \& Adaptive Management (IJITAM) vol. 1, 2013.

[36] S. B. B. Rammyaa "A REVIEW OF POSITION BASED ROUTING PROTOCOLS FOR MOBILE AD 
HOC NETWORKS," International Journal of Network and Mobile Technologies, vol. 2, pp. 77-81, 2011.

I. Stojmenovic, "Position-based routing in ad hoc networks," IEEE communications magazine, vol. 40, pp. 128-134, 2002.

[38] A. M. Popescu, I. G. Tudorache, B. Peng, and A. H. Kemp, "Surveying position based routing protocols for wireless sensor and ad-hoc networks," International Journal of Communication Networks and Information Security, vol. 4, p. 41, 2012.

[39] S. Kaur and A. K. Gupta, "Position based routing in mobile Ad-hoc networks: An overview," IJCST, vol. 3, 2012.

[40] A. Gupta and S. D. Sharma, "A Survey on Location Based Routing Protocols in Mobile Ad-hoc Networks," Int. J. Comput. Sci. Inforrn. Technol, vol. 5, pp. 994997, 2014

[41] C. Maihofer, "A survey of geocast routing protocols," IEEE Communications Surveys \& Tutorials, vol. 6, pp. 32-42, 2004.

[42] R. K. Yadav, D. Gupta, and R. Singh, "Literature Survey on energy efficient routing protocols for mobile ad hoc networks," International Journal of Innovations and Advancement in Computer Science, 2015.

[43] S. Kumara, E. S. Ranab, and E. A. Sharmac, "Energy Efficient Routing Techniques for Mobile Ad Hoc Networks," 2014.

[44] S. Mishra and B. K. Pattanayak, "Power Aware Routing In Mobile Ad Hoc Networks-A Survey," ARPN Journal of Engineering and Applied Sciences, vol. 8, pp. 173189, 2013.

[45] S. Mishra and B. K. Pattanayak, "Power Aware Routing In Mobile Ad Hoc Networks-A Survey," ARPN Journal of Engineering and Applied Sciences, vol. 8, 2013.

[46] A. Kumaravel and M. Chandrasekaran, "A complete study on power aware routing protocol for mobile adhoc network," IOSR Journal of Electrical and Electronics Engineering, vol. 1, pp. 71-5, 2014.

[47] V. Bapuji, S. Sharma, R. L. Naik, D. Ramesh, and B. Manjula, "Quality of service for mobile Ad-hoc wireless networks," international Journal on computer Science and Engineering, vol. 3, pp. 1573-1577, 2011.

[48] C.-C. Huang and S.-C. Lo, "A comprehensive survey of multicast routing protocols for mobile ad hoc networks," 網際網路技術學刊, vol. 9, pp. 25-34, 2008.

[49] E. M. Royer and C. E. Perkins, "Multicast operation of the ad-hoc on-demand distance vector routing protocol," in Proceedings of the 5th annual ACM/IEEE international conference on Mobile computing and networking, 1999, pp. 207-218.

[50] X. Zou, B. Ramamurthy, and S. Magliveras, "Routing techniques in wireless ad hoc networks classification and comparison," in Proceedings of the Sixth World Multiconference on Systemics, Cybernetics and Informatics, SCI, 2002, pp. 1-6.

[51] Y. Yi, "On-demand multicast routing protocol (ODMRP) for ad hoc networks," draft-yi-manet-odmrp00, 2003.

[52] M. R. BAKER and M. A. Akcayol, "A survey of multicast routing protocols in Ad-hoc networks," Gazi University Journal of Science, vol. 24, pp. 451-462, 2011. 